University of Wollongong

Research Online

Faculty of Engineering and Information

Faculty of Engineering and Information

Sciences - Papers: Part B

Sciences

2019

Investigation of engineering properties of normal and high strength fly ash based geopolymer and alkali-activated slag concrete compared to ordinary Portland cement concrete

\author{
Nabeel Farhan \\ University of Wollongong, naf010@uowmail.edu.au \\ M Neaz Sheikh \\ University of Wollongong, msheikh@uow.edu.au \\ Muhammad N. S Hadi \\ University of Wollongong, mhadi@uow.edu.au
}

Follow this and additional works at: https://ro.uow.edu.au/eispapers1

Part of the Engineering Commons, and the Science and Technology Studies Commons

Research Online is the open access institutional repository for the University of Wollongong. For further information contact the UOW Library: research-pubs@uow.edu.au 


\title{
Investigation of engineering properties of normal and high strength fly ash based geopolymer and alkali-activated slag concrete compared to ordinary Portland cement concrete
}

\begin{abstract}
Fly ash-based geopolymer (FAGP) and alkali-activated slag (AAS) concrete are produced by mixing alkaline solutions with aluminosilicate materials. As the FAGP and AAS concrete are free of Portland cement, they have a low carbon footprint and consume low energy during the production process. This paper compares the engineering properties of normal strength and high strength FAGP and AAS concrete with OPC concrete. The engineering properties considered in this study included workability, dry density, ultrasonic pulse velocity (UPV), compressive strength, indirect tensile strength, flexural strength, direct tensile strength, and stress-strain behaviour in compression and direct tension. Microstructural observations using scanning electronic microscopy (SEM) are also presented. It was found that the dry density and UPV of FAGP and AAS concrete were lower than those of OPC concrete of similar compressive strength. The tensile strength of FAGP and AAS concrete was comparable to the tensile strength of OPC concrete when the compressive strength of the concrete was about $35 \mathrm{MPa}$ (normal strength concrete). However, the tensile strength of FAGP and AAS concrete was higher than the tensile strength of OPC concrete when the compressive strength of concrete was about $65 \mathrm{MPa}$ (high strength concrete). The modulus of elasticity of FAGP and AAS concrete in compression and direct tension was lower than the modulus of elasticity of OPC concrete of similar compressive strength. The SEM results indicated that the microstructures of FAGP and AAS concrete were more compact and homogeneous than the microstructures of OPC concrete at 7 days, but less compact and homogeneous than the microstructures of OPC concrete at 28 days for the concrete of similar compressive strength.
\end{abstract}

\section{Keywords}

normal, properties, engineering, investigation, ordinary, compared, concrete, cement, slag, portland, alkaliactivated, geopolymer, ash, fly, strength, high

\section{Disciplines \\ Engineering | Science and Technology Studies}

\section{Publication Details}

Farhan, N., Sheikh, M. Neaz. \& Hadi, M. N. S. (2019). Investigation of engineering properties of normal and high strength fly ash based geopolymer and alkali-activated slag concrete compared to ordinary Portland cement concrete. Construction and Building Materials, 196 26-42. 


\section{Ash Based Geopolymer and Alkali-Activated Slag Concrete Compared to}

Nabeel A. Farhan ${ }^{1}$, M. Neaz Sheikh², Muhammad N.S. Hadi ${ }^{3 *}$,

${ }^{1}$ Ph.D. Candidate, School of Civil, Mining and Environmental Engineering, University of 7 Wollongong, Australia

${ }^{2}$ Associate Professor, School of Civil, Mining and Environmental Engineering, University of Wollongong, Australia

${ }^{3 *}$ Associate Professor, School of Civil, Mining and Environmental Engineering, University of Wollongong, Australia

Correspondence:

Muhammad N. S. Hadi

School of Civil, Mining \& Environmental Engineering

University of Wollongong, Australia

E-mail: mhadi@uow.edu.au

* Corresponding author 

Ash Based Geopolymer and Alkali-Activated Slag Concrete Compared to

\section{Ordinary Portland Cement Concrete}

29

\section{Abstract}

Fly ash-based geopolymer (FAGP) and alkali-activated slag (AAS) concrete are produced by mixing alkaline solutions with aluminosilicate materials. As the FAGP and AAS concrete are free of Portland cement, they have a low carbon footprint and consume low energy during the production process. This paper compares the engineering properties of normal strength and high strength FAGP and AAS concrete with OPC concrete. The engineering properties considered in this study included workability, dry density, ultrasonic pulse velocity (UPV), compressive strength, indirect tensile strength, flexural strength, direct tensile strength, and stress-strain behaviour in compression and direct tension. Microstructural observations using scanning electronic microscopy (SEM) are also presented. It was found that the dry density and UPV of FAGP and AAS concrete were lower than those of OPC concrete of similar compressive strength. The tensile strength of FAGP and AAS concrete was comparable to the tensile strength of OPC concrete when the compressive strength of the concrete was about 35 $\mathrm{MPa}$ (normal strength concrete). However, the tensile strength of FAGP and AAS concrete was higher than the tensile strength of OPC concrete when the compressive strength of concrete was about $65 \mathrm{MPa}$ (high strength concrete). The modulus of elasticity of FAGP and AAS concrete in compression and direct tension was lower than the modulus of elasticity of OPC concrete of similar compressive strength. The SEM results indicated that the microstructures of FAGP and AAS concrete were more compact and homogeneous than the microstructures of OPC concrete at 7 days, but less compact and homogeneous than the microstructures of OPC concrete at 28 days for the concrete of similar compressive strength. 
51 Keywords: Fly ash-based geopolymer concrete; Alkali-activated slag concrete; Engineering properties; High strength; Normal strength

\section{Introduction}

Cement is the main material used in the production of concrete. The production process of cement is associated with the consumption of high energy and natural resources. The production of cement is associated with the emission of greenhouse gases including methane, nitrous oxide and carbon dioxide into the atmosphere. Indeed, it is estimated that the production of one tonne of cement requires about 1.5 tonnes of raw materials and releases nearly one tonne of carbon dioxide into the atmosphere [1-4]. Thus, the use of aluminosilicate materials as an alternative to the cement has become necessary, especially to reduce the carbon dioxide emissions into the atmosphere. Many research studies were carried out to develop new and greener materials as alternatives to cement such as geopolymer and alkali activated binder. Fly ash (FA) and Ground Granulated Blast Furnace Slag (GGBS) are the most common aluminosilicate materials used in the production of fly ash based geopolymer (FAGP) and alkali-activated slag (AAS) concrete. The FAGP and AAS concrete are green concrete without Portland cement. The FAGP and AAS concrete can be produced by blending an alkaline solution with aluminosilicate materials such as FA and GGBS. The FAGP and AAS concrete are proven to have comparable mechanical properties to the OPC concrete but with reduced greenhouse gas emissions. The use of FAGP or AAS concrete can reduce $\mathrm{CO}_{2}$ emissions into atmosphere associated with the production of concrete by $60-80 \%$ [5-7].

Fernandez-Jimenez et al. [8] studied the engineering properties of heat cured FAGP concrete and compared with the engineering properties of OPC concrete. The test results showed that the indirect tensile and flexural strengths of FAGP concrete were higher than those of OPC 
concrete. However, the modulus of elasticity of FAGP concrete was lower than the modulus of elasticity of OPC concrete. Hardjito and Rangan [9] showed that FAGP concrete achieved similar compressive strength, higher indirect tensile and flexural strengths and lower modulus of elasticity than OPC concrete. Neupane et al. [10] studied the engineering properties of heat cured FAGP concrete and compared with the engineering properties of OPC concrete. It was found that the indirect tensile and flexural strengths of FAGP concrete were higher than those of OPC concrete, whereas the modulus of elasticity of FAGP concrete was similar to the modulus of elasticity of OPC concrete. Diaz-Loya et al. [11] investigated the engineering properties of heat cured FAGP concrete. The engineering properties of heat cured FAGP concrete were found to be similar to those of OPC concrete. The test results also showed that the equations in the existing design standards for OPC concrete could be used for FAGP concrete to determine the indirect tensile strength, flexural strength, and the modulus of elasticity.

Several studies investigated the engineering properties of AAS concrete and compared with the engineering properties of OPC concrete. Bernal et al. [12] studied the engineering properties of AAS concrete produced in the laboratory at an ambient condition and compared with the engineering properties of OPC concrete. The compressive strength of AAS concrete was found to be comparable to the compressive strength of OPC concrete, but the indirect tensile and flexural strengths were slightly higher than those of OPC concrete. Lee et al. [13] studied the engineering properties of AAS concrete produced in the laboratory at an ambient condition and showed that the indirect tensile strength and modulus of elasticity of AAS concrete were slightly lower than those of OPC concrete. Chi [14] investigated the mechanical and durability performance of AAS concrete and compared with the mechanical and durability performance of OPC concrete. The test results showed that AAS concrete could be produced 
with superior engineering properties (compressive strength, splitting tensile strength, drying shrinkage, sulphate attack resistance, and high-temperature resistance) and the durability to those of OPC concrete.

Most of the previous studies focused either on the engineering properties of FAGP concrete or the engineering properties of AAS concrete and compared with the engineering properties of OPC concrete. The engineering properties of FAGP and AAS concrete compared to the OPC concrete have not been adequately investigated in the available literature. Very limited information is currently available for the engineering properties of FAGP and AAS concrete compared to the OPC concrete. An extensive review of literature revealed, none of the research studies investigated the engineering properties of normal strength and high strength FAGP and AAS concrete compared with the engineering properties of OPC concrete. A complete understanding of the engineering properties of FAGP and AAS concrete is important for the design and field implementation of eco-friendly concrete structures. This paper compares the engineering properties of normal strength and high strength FAGP and AAS concrete with the engineering properties of normal strength and high strength OPC concrete. Microstructural investigations using scanning electronic microscopy (SEM) are also carried out. The equations in the existing standards for OPC concrete were used to calculate indirect tensile strength, flexural strength and modulus of elasticity of FAGP and AAS concrete and compared with the experimental results. It is noted that the development of mathematical models for the engineering properties of FAGP and AAS concrete is considered beyond the scope of this paper. 


\section{Experimental investigation}

127

128

\subsection{Materials used}

The materials used in this study were FA, GGBS and General-purpose cement. The FA supplied by Gladstone Power Station, Australia was used as the source material for FAGP concrete. The GGBS supplied by the Australian Slag Association was used as the source material for AAS concrete. General purpose cement was used as the binder for OPC concrete. The chemical composition of FA and GGBS was determined by X-Ray Fluorescent (XRF) and is shown in Table 1. Chemical analyses of FA and GGBS were carried out in the School of Earth and Environmental Sciences at the University of Wollongong, Australia. Table 1 shows that FA contains less than $5 \%$ calcium oxide $(\mathrm{CaO})$. The sum of $\mathrm{Al}_{2} \mathrm{O}, \mathrm{SiO}_{2}$ and $\mathrm{Fe}_{2} \mathrm{O}_{3}$ contents was higher than $70 \%$ of the FA components. The $\mathrm{CaO}$ content was less than $8 \%$ of the FA components. Hence, the FA used in this study can be classified as Type 'F' according to ASTM C618-08 [15]. The chemical compositions of the OPC provided by cement Australia are shown in Table 2.

Crushed coarse aggregate with $10 \mathrm{~mm}$ maximum aggregate size in the saturated surface dry condition and locally available river sand (fine aggregate) were used to prepare all the test specimens. The alkaline activator was a mixture of sodium hydroxide $(\mathrm{NaOH})$ and sodium silicate $\left(\mathrm{Na}_{2} \mathrm{SiO}_{3}\right)$ solution. Sodium hydroxide $(\mathrm{NaOH})$ pellets were dissolved in potable water to prepare the sodium hydroxide $(\mathrm{NaOH})$ solution with different concentrations. Sodium silicate solution $\left(\mathrm{Na}_{2} \mathrm{SiO}_{3}\right)$ with a specific gravity of 1.53 and an activator modulus (Ms) of 2.0 $\left(\mathrm{Ms}=\mathrm{SiO}_{2} / \mathrm{Na}_{2} \mathrm{O} ; \mathrm{SiO}_{2}=29.4 \%\right.$ and $\left.\mathrm{Na}_{2} \mathrm{O}=14.7 \%\right)$ was supplied by PQ Australia. To obtain fresh concrete with high workability, commercially available high range water reducer (Glenium 8700) supplied by BASF, Australia was used in this study. 


\subsection{Preparation of concrete mixes}

Three types of concrete were used in this study: FAGP, AAS and OPC concrete. The design compressive strengths of the concrete at 28 days were $35 \mathrm{MPa}$ (normal strength concrete, NSC) and $65 \mathrm{MPa}$ (high strength concrete, HSC). The total amount of aggregate in the FAGP and AAS concrete was between $60-80 \%$ of the mass of the concrete. The amount of aggregate varied depending on the amount of binder (FA and GGBS) and alkaline activator. The concentration of $\mathrm{NaOH}$ used to prepare the normal strength and high strength FAGP concrete was 12 moles/litre (M) and 14 moles/litre (M), respectively. The ratio of sodium silicate $\left(\mathrm{Na}_{2} \mathrm{SiO}_{3}\right)$ to sodium hydroxide $(\mathrm{NaOH})$ was fixed at 2 . The concentration of $\mathrm{NaOH}$ used to prepare the normal strength and high strength AAS concrete was $12 \mathrm{M}$ and $14 \mathrm{M}$, respectively. The ratio of sodium silicate $\left(\mathrm{Na}_{2} \mathrm{SiO}_{3}\right)$ to sodium hydroxide $(\mathrm{NaOH})$ was fixed at 2.5. Extra water and high range water reducer were added into the concrete mixes to obtain consistent workability during the casting of concrete.

For the normal strength OPC concrete, the mix proportions by weight of cement, fine aggregate, and coarse aggregate were 1:2.2:3.3 with a maximum aggregate size of $10 \mathrm{~mm}$ and water to cement ratio of 0.52 . For the high strength OPC concrete, the mix proportions by weight of cement, fine aggregate, and coarse aggregate were 1:1.3:2.3 with a maximum aggregate size of $10 \mathrm{~mm}$ and water to cement ratio of 0.30 . Table 3 shows the mix proportions of FAGP, AAS and OPC concrete mixes.

The concrete was mixed in an electrical pan mixer with a capacity of $0.1 \mathrm{~m}^{3}$ in the High Bay Laboratory at the University of Wollongong, Australia. To produce FAGP and AAS concrete, the dry materials including FA or GGBS, fine aggregates and coarse aggregates were mixed for about four minutes. Afterwards, alkaline activator, water and the high range water reducer 
were added to the dry mix, which was then mixed for another five minutes for a uniform consistency of concrete. These fresh mixes were then poured into Polyvinyl chloride (PVC) moulds to prepare specimens to test the dry density, ultrasonic pulse velocity (UPV), compressive strength, indirect tensile strength and stress-strain behaviour under compression. Also, the fresh concrete was poured into plywood moulds to prepare the specimen for the flexural and direct tensile strength tests. These mixes were then vibrated on a vibration table for 1 minute to remove air bubbles and to ensure that the concrete was adequately compacted. In total, 24 cylinder specimens with $100 \mathrm{~mm}$ diameter and $200 \mathrm{~mm}$ height were cast to test the dry density, ultrasonic pulse velocity (UPV) and compressive strength of FAGP and AAS concrete. In addition, 48 cylinder specimens with $150 \mathrm{~mm}$ diameter and $300 \mathrm{~mm}$ height were cast to test the indirect tensile strength and stress-strain behaviour. Moreover, 48 prism specimens with a cross-section of $100 \mathrm{~mm} \times 100 \mathrm{~mm}$ and a length of $500 \mathrm{~mm}$ were cast for the flexural and direct tensile strength tests. After casting, the FAGP and AAS concrete specimens were kept in the moulds and left in the laboratory at the ambient condition (temperature of 23 $\pm 3^{\circ} \mathrm{C}$ ) for 24 hours. The FAGP concrete specimens were heat cured at $80^{\circ} \mathrm{C}$ for 24 hours. Then the specimens were removed from the moulds and left in the laboratory until the time of testing. The AAS concrete specimens were removed from the moulds after 24 hours of casting and were left in the laboratory at the ambient condition until the time of testing.

The dry material (cement, fine and coarse aggregates) for OPC concrete were mixed for about four minutes and water and high range water reducer were slowly added. The mixing continued for another five minutes for a uniform consistency of concrete. The fresh mix was then poured into the steel moulds and vibrated for 1 minute on a vibration table to remove any air bubbles and ensure that the concrete was aduaqatly compacted. Twelve cylinder specimens of $100 \mathrm{~mm}$ diameter and $200 \mathrm{~mm}$ height were cast with OPC concrete to test dry density, ultrasonic pulse 
velocity (UPV) and compressive strength. In addition, 24-cylinder specimens of $150 \mathrm{~mm}$

202

203

204 diameter and $300 \mathrm{~mm}$ height were cast to test the indirect tensile strength and stress-strain behaviour under compression. Twenty-four prism specimens with a cross-section of $100 \mathrm{~mm}$ $\times 100 \mathrm{~mm}$ and a length of $500 \mathrm{~mm}$ were cast for the flexural and direct tensile strength tests. After casting, the OPC concrete specimens were kept in the moulds and left in the laboratory at the ambient condition (temperatures of $23 \pm 3^{\circ} \mathrm{C}$ ) for 24 hours. Afterwards, the specimens were removed from the moulds and cured in water until the time of testing. The preparation of FAGP and AAS concrete specimens are shown in Fig. 1.

\section{Test methods}

\subsection{Microstructural analysis}

The microstructure of primary materials (i.e. FA, GGBS and OPC) and the microstructure of FAGP, AAS and OPC concrete specimens were assessed using a Scanning Electron Microscope (SEM). The SEM analysis were carried out using JEOL-JSM 6490LV at the Electron Micro Centre (EMC), University of Wollongong, Australia. The samples for SEM investigation of FAGP, AAS and OPC concrete specimens were taken from the broken particles of the specimens which were tested under compressive strength. The samples were cut for $20 \mathrm{~mm}$ in diameter and $10 \mathrm{~mm}$ high. The samples were left in the laboratory at the ambient condition for 7 days before testing to ensure that the samples were adequately dried and then coated with gold for SEM imaging.

\subsection{Tests for fresh concrete}

Slump tests were carried out according to AS 1012.3.1-1998 [16] to determine the consistency of the mixes. The workability of fresh concrete was determined by the slump test using a steel 
cone with a top diameter of $100 \mathrm{~mm}$ and a bottom diameter of $200 \mathrm{~mm}$ and a height of 300 $\mathrm{mm}$.

\subsection{Tests for hardened concrete}

To evaluate the engineering properties of hardened FAGP and AAS concrete and compare with the engineering properties of OPC concrete, dry density, ultrasonic pulse velocity, compressive strength, indirect tensile strength, flexural strength, direct tensile strength and stress-strain behaviour tests were carried out. The density of the hardened concrete was measured according to AS 1012.12.2-1998 [17]. The density test was carried out on three specimens of $100 \mathrm{~mm}$ in diameter and $200 \mathrm{~mm}$ in height for each mix and the average density was recorded. Ultrasonic Pulse Velocity (UPV) tests were carried out in accordance with ASTM C597-2009 [18]. The UPV test was carried out on three specimens of $100 \mathrm{~mm}$ in diameter and $200 \mathrm{~mm}$ in height for each mix and the average UPV was recorded. Three specimens were tested and the average result has been reported to evaluate the compressive strength and quality of the concrete based on the speed of a stress wave passing through a solid medium. The speed of the stress wave is related to the density of the concrete. The UPV test was carried out with a Portable Ultrasonic Non-destructive Digital Indicating Test set up.

The compressive strength tests were carried out with the Avery compression testing machine of $1800 \mathrm{kN}$ capacity according to AS 1012.9-1999 [19]. Before testing, the specimens were capped with high strength plaster to ensure a uniform loading surface. Three specimens from each mix were tested and the average compressive strength was recorded. Indirect tensile strength tests were carried out to determine the tensile strength of concrete according to AS 1012.10-2000 [20]. The specimens were tested with the Avery compression testing machine at a loading rate of $106 \mathrm{kN} / \mathrm{min}$ until the specimen failed. Three specimens from each mix were 
tested and the average indirect tensile strength was recorded as the tensile strength of concrete.

251 The four-point bending tests were carried out according to AS 1012.11-2000 [21] using an Avery 50 tonne testing machine at a loading rate of $2 \mathrm{kN} / \mathrm{sec}$. The specimens were tested until failure. The average measurement of three specimens was recorded as the flexural strength of concrete.

The direct tensile strength of the specimens was determined according to the test setup proposed by Alhussainy et al. [22]. The direct tensile test was carried out with a $500 \mathrm{kN}$ Universal Instron testing machine at $0.1 \mathrm{~mm} / \mathrm{min}$. To ensure that the specimens fractured in the middle, the cross-sectional area in the middle was reduced by $20 \%$ using two wooden triangular prisms. Three specimens were tested for each mix and the average direct tensile strengths have been reported.

The stress-strain behaviour of specimens (150 mm diameter by $300 \mathrm{~mm}$ high) under compression was determined according to AS 1012.17-2014 [23] with a $5000 \mathrm{kN}$ Denison compression testing machine at a loading rate of $0.3 \mathrm{~mm} / \mathrm{min}$. Three linear variable differential transducers (LVDT) were used to record the axial deformation of the specimens. The specimens were capped before testing with high strength plaster to ensure uniform loading surfaces.

\section{Results and Discussion}

\subsection{Microstructural Development}

272 The microscopic characteristics of primary materials (i.e., FA, GGBS and OPC) used in the 273 production of FAGP, AAS and OPC concrete are shown in Fig. 2. Figure 2 (a) shows that the 274 FA consists mainly of glassy, spherical particles. The surfaces of the particles appear to be 
dense and smooth. The OPC and GGBS particles consist mainly of clear edges and angular shapes (Fig. 2 b and c).

The microstructural development of normal strength and high strength FAGP, AAS and OPC concrete are shown in Figs. (3-5). The microstructure of normal strength and high strength FAGP concrete showed an abundance of unreacted spherical shaped particles of fly ash and a loose amorphous structure with visible micro-cavities in the FAGP concrete specimens at 7 days (Fig. 3). These visible micro-cavities at 7 days are due to the evaporation of water from FAGP concrete specimens during the heat curing stage. The microstructure of FAGP concrete at 28 days showed less unreacted particles of fly ash. The structures of the geopolymer mixes look denser and more compact due to some additional geopolymerisation and the formation of aluminosilicate gel in the FAGP concrete specimens. The aluminosilicate gel diffused through the micro-cavities to fill the interior voids in the FAGP concrete specimens and increase adhesion with particles of geopolymer matrices, which resulted in a highly compacted and homogeneous structure [24].

The microstructural development of normal strength and high strength AAS concrete displayed heterogeneous gel matrices at 7 days (Fig. 4). Figure 4 shows that most of the GGBS particles were partially dissolved by the alkaline activator to form C-S-H gel. Small microcracks were formed on the surface of the AAS microstructure due to a rapid reaction between the alkaline activator and GGBS particles in the initial period $[12,25]$. After 28 days, the microstructural development of AAS concrete showed more C-S-H gel due to the dissolution of the remaining unreacted GGBS particles. It is noted that, as the reaction continued, the small microcracks on the surface of the AAS microstructure were filled with C-S-H gel. This helped to bridge the microcracks on the surface of AAS microstructure. Hence, the density and uniformity of AAS 
microstructure increased and a more compacted and homogeneous structure was formed between 7 and 28 days. The findings demonstrated in this study are consistent with those reported in few previous studies $[25,26]$.

The microstructure of normal strength and high strength OPC concrete was less compact and homogeneous than FAGP and AAS concrete at 7 days (Fig. 5). However, the microstructural development of OPC concrete at 28 days achieved denser microstructures and was more homogeneous than FAGP and AAS concrete at 28 days. Less unreacted OPC particles and no cracks were observed in the OPC matrices at 28 days.

\subsection{Workability}

The workability of fresh FAGP, AAS and OPC concrete was measured using slump test. The workability of fresh FAGP, AAS and OPC concrete was determined immediately after mixing the ingredients of the concrete. For the normal strength concrete (NSC), the fresh FAGP, AAS and OPC concrete were handled, placed, compacted and finished easily. It was observed that FAGP concrete exhibited the highest workability compared to AAS and OPC concrete. During the slump tests, it was observed that the FAGP concrete collapsed during the slump test as soon as the slump cone was lifted. This was attributed to the spherical shaped particles of fly ash, which increased the followability of the mixes (Fig. 2a). In addition, the sodium silicate solution and the added water contributed further to the high flowability [27, 28].

For the high strength concrete (HSC), the workability of FAGP, AAS and OPC concrete decreased with the decrease in the liquid/binder and increase in the binder content. The decrease in the workability was more significant for AAS and OPC concrete. This can be attributed to the angular shape of the GGBS and OPC particles, which increased the internal 
shear friction of the mixture [29]. It was also observed that, with the increase in the $\mathrm{NaOH}$ concentration, the viscosity of the alkaline activator solution was increased, which made the mix very sticky. As a result, the workability of the FAGP and AAS concrete decreased.

\subsection{Dry density}

The dry density of FAGP, AAS and OPC concrete at 7 and 28 days are presented in Table 4. For the NSC, the average dry density of FAGP, AAS and OPC concrete at 7 days was 2373 $\mathrm{kg} / \mathrm{m}^{3}, 2389 \mathrm{~kg} / \mathrm{m}^{3}$ and $2368 \mathrm{~kg} / \mathrm{m}^{3}$, respectively. The dry density of FAGP, AAS and OPC concrete increased as the age of the concrete increased. The average density of FAGP concrete increased from $2373 \mathrm{~kg} / \mathrm{m}^{3}$ at 7 days to $2378 \mathrm{~kg} / \mathrm{m}^{3}$ at 28 days with an overall increase of $0.21 \%$. The average density of AAS concrete increased from $2389 \mathrm{~kg} / \mathrm{m}^{3}$ at 7 days to $2403 \mathrm{~kg} / \mathrm{m}^{3}$ at 28 days with an overall increase of $0.58 \%$. The average density of OPC concrete increased from $2368 \mathrm{~kg} / \mathrm{m}^{3}$ at 7 days to $2415 \mathrm{~kg} / \mathrm{m}^{3}$ at 28 days with an overall increase of $1.98 \%$. The OPC concrete achieved the highest dry density compared to the dry density of FAGP and AAS concrete at 28 days.

For the HSC, the average dry density of FAGP, AAS and OPC concrete at 7 days were 2381 $\mathrm{kg} / \mathrm{m}^{3}, 2420 \mathrm{~kg} / \mathrm{m}^{3}$ and $2401 \mathrm{~kg} / \mathrm{m}^{3}$, respectively. The dry density of FAGP, AAS and OPC concrete increased as the concrete age increased. The average density of FAGP concrete increased from $2381 \mathrm{~kg} / \mathrm{m}^{3}$ at 7 days to $2384 \mathrm{~kg} / \mathrm{m}^{3}$ at 28 days, while the average density of AAS concrete increased from $2420 \mathrm{~kg} / \mathrm{m}^{3}$ at 7 days to $2432 \mathrm{~kg} / \mathrm{m}^{3}$ at 28 days. This increase in density was about $0.13 \%$ and $0.50 \%$ for FAGP and AAS concrete, respectively. The average density of OPC concrete increased from $2401 \mathrm{~kg} / \mathrm{m}^{3}$ at 7 days to $2443 \mathrm{~kg} / \mathrm{m}^{3}$ at 28 days with an overall increase of $1.75 \%$. These results indicated that there were slight increases in the density of normal strength and high strength FAGP, AAS and OPC concrete over time. Whereas, the 
average density of FAGP and AAS concrete was less than the average density of OPC concrete with similar compressive strengths. These findings were confirmed by SEM analyses. The SEM images showed that FAGP and AAS concrete were less dense, less compacted, and had less homogeneous microstructures than OPC at 28 days (Figs. 3-5).

\subsection{Ultrasonic Pulse Velocity}

The ultrasonic pulse velocity (UPV) test is used to evaluate the strength and quality of concrete. The pulse velocity depends mostly on the density and properties of concrete. The pulse velocity of FAGP, AAS and OPC concrete at 7 and 28 days are shown in Table 4. Table 4 indicates that the pulse velocity of FAGP, AAS and OPC concrete increased as the concrete age increased. For the NSC, the average pulse velocity of FAGP concrete increased from $3.14 \mathrm{~km} / \mathrm{s}$ at 7 days to $3.20 \mathrm{~km} / \mathrm{s}$ at 28 days, while for AAS concrete the average pulse velocity increased from 3.18 $\mathrm{km} / \mathrm{s}$ at 7 days to $3.31 \mathrm{~km} / \mathrm{s}$ at 28 days. The increase in the pulse velocity of FAGP and AAS concrete was about $1.91 \%$ and $4.1 \%$, respectively. The average pulse velocity of OPC concrete increased from $3.30 \mathrm{~km} / \mathrm{s}$ at 7 days to $3.52 \mathrm{~km} / \mathrm{s}$ at 28 days with an overall increase of $6.67 \%$. The ultrasonic pulse velocity test results indicated that the quality of the concrete improved over time. The quality of the concrete can be evaluated according to the International Atomic Energy Agency [30], as shown in Table 5. Based on the IAEA, OPC concrete can be classified as "medium" quality at 7 days, because the pulse velocity was $3.30 \mathrm{~km} / \mathrm{s}$. As the pulse velocity increased to $3.52 \mathrm{~km} / \mathrm{s}$ at 28 days, the concrete can be classified as "good" quality. The average pulse velocity of FAGP and AAS concrete is less than the average pulse velocity of OPC concrete, which was between $3-3.5 \mathrm{~km} / \mathrm{s}$ at 7 and 28 days. Hence, the FAGP and AAS concrete are classified as "medium" quality concrete [30]. 
For the HSC, the average pulse velocity of FAGP concrete increased from $3.82 \mathrm{~km} / \mathrm{s}$ at 7 days to $3.93 \mathrm{~km} / \mathrm{s}$ at 28 days with an increase of $2.88 \%$. The average pulse velocity of AAS concrete increased from $3.78 \mathrm{~km} / \mathrm{s}$ at 7 days to $3.98 \mathrm{~km} / \mathrm{s}$ at 28 days with an increase of $5.29 \%$. The average pulse velocity of OPC concrete increased from $3.87 \mathrm{~km} / \mathrm{s}$ at 7 days to $4.15 \mathrm{~km} / \mathrm{s}$ at 28 days with an increase of $7.23 \%$. The pulse velocity of FAGP concrete was lower than the pulse velocity of OPC concrete at 7 and 28 days. Similarly, the pulse velocity of AAS concrete was lower than the pulse velocity of OPC concrete at 7 and 28 days. Since the pulse velocity of FAGP, AAS and OPC concrete at 7 and 28 days ranged between $3.5-4.5 \mathrm{~km} / \mathrm{s}$, they can be classified as "good" quality concrete [30].

\subsection{Compressive strength}

The average compressive strength of FAGP, AAS and OPC concrete at 7 and 28 days are shown in Table 4. The compressive strength of AAS and FAGP concrete is comparable to the OPC concrete at 28 days (Table 4). For the NSC with the design compressive strength of 35 $\mathrm{MPa}$, the average compressive strength of FAGP, AAS and OPC concrete at 7 days was 33.90 MPa, 29.03 MPa and 26.51 MPa, respectively. The FAGP concrete achieved the highest initial compressive strength at 7 days, which was $94.44 \%$ of the compressive strength at 28 days. However, AAS and OPC concrete obtained a lower initial compressive strength than FAGP concrete at 7 days, which were $79.66 \%$ and $74.01 \%$ of the compressive strength at 28 days. The compressive strength of FAGP, AAS and OPC concrete increased with time (Table 4), the average compressive strength of FAGP, AAS and OPC concrete at 28 days was 35.91, 36.44 $\mathrm{MPa}$ and $35.82 \mathrm{MPa}$, respectively.

For the HSC with the design compressive strength of $65 \mathrm{MPa}$, the average compressive strength of FAGP, AAS and OPC concrete at 7 days was $61.71 \mathrm{MPa}, 53.68 \mathrm{MPa}$ and $50.73 \mathrm{MPa}$, 
respectively. The FAGP concrete achieved the highest initial compressive strength at 7 days, which was $94.53 \%$ of the compressive strength at 28 days. The compressive strength of AAS and OPC concrete at 7 days were $81.20 \%$ and $76.06 \%$, respectively, of the compressive strength at 28 days. The compressive strengths of FAGP, AAS and OPC concrete increased with time. The average compressive strengths of FAGP, AAS and OPC concrete at 28 days were 65.28, 66.12 MPa, and 66.69 MPa, respectively. For the NSC and HSC, FAGP concrete developed most of its compressive strength at 7 days although there was a slight increase in the compressive strength at 28 days (Table 4) due to heat curing, which accelerated the geopolymerisation (dissolution mechanism) reaction and increased the compressive strength. The findings of this study agree with Adam [28], in which it was shown that FAGP concrete developed most of its compressive strength at 7 days and there was a marginal increase in the compressive strength at 28 days [28].

\subsection{Indirect tensile strength}

The indirect tensile strength of FAGP, AAS and OPC concrete was determined at 7 and 28 days, and the results are reported in Table 4. For the NSC, the average indirect tensile strength of FAGP, AAS and OPC concrete at 7 days was $3.37 \mathrm{MPa}, 2.93 \mathrm{MPa}$ and $2.66 \mathrm{MPa}$, respectively. The FAGP concrete achieved the highest indirect tensile strength at 7 days. The indirect tensile strength of FAGP, AAS and OPC concrete increased as the concrete age increased. The average indirect tensile strength of FAGP, AAS and OPC concrete at 28 days was 3.58 MPa, 3.55 MPa and 3.51 MPa, respectively. The indirect tensile strength of FAGP, AAS and OPC concrete increased by $6.23 \%, 21.16 \%$ and $31.95 \%$ at 28 days, respectively, compared to the indirect tensile strengths at 7 days. When compared with the OPC concrete, the FAGP and AAS concrete achieved very similar indirect tensile strength at 28 days (Table 4). 
For the HSC, the average indirect tensile strength of FAGP, AAS and OPC concrete at 7 days was 5.32 MPa, 4.49 MPa and 3.78 MPa, respectively. The FAGP concrete achieved the highest indirect tensile strength at 7 days. The indirect tensile strength of FAGP, AAS and OPC concrete increased with age. The average indirect tensile strength of FAGP, AAS and OPC concrete at 28 days was 5.73 MPa, 5.23 MPa and 4.94 MPa, respectively. The indirect tensile strength of FAGP, AAS and OPC concrete increased by $7.71 \%, 16.48 \%$ and $30.68 \%$ at 28 days, respectively. From the test results, it can be observed that the FAGP and AAS concrete achieved about $15.99 \%$ and $5.87 \%$, respectively, higher indirect tensile strength at 28 days than OPC concrete of similar compressive strength. These results are consistent with previous studies carried out on FAGP and AAS concrete. Ryu et al. [5] examined the indirect tensile strength of fly ash based geopolymer concrete and found that the indirect tensile strength of geopolymer concrete was higher than the indirect tensile strength of OPC concrete. Bernal et al. [31] reported that AAS concrete achieved a higher indirect tensile strength than OPC concrete at 28 days.

\subsection{Flexural strength}

The flexural strength is generally higher than the indirect tensile strength as specified in the ACI 318-14 [32] and AS 3600-2009 [33]. The average flexural strengths of FAGP, AAS and OPC concrete at 7 and 28 days are shown in Table 4. For the NSC, the average flexural strength of FAGP, AAS and OPC concrete at 7 days was $3.57 \mathrm{MPa}, 3.21 \mathrm{MPa}$ and $3.06 \mathrm{MPa}$, respectively. The FAGP concrete achieved the highest flexural strength at 7 days. The flexural strength of FAGP, AAS and OPC concrete increased with age. The average flexural strength of FAGP, AAS and OPC concrete at 28 days was found to be $3.81 \mathrm{MPa}, 3.79 \mathrm{MPa}$ and 3.78 MPa, respectively. The flexural strength of FAGP, AAS and OPC concrete increased by $6.72 \%$, 

the test results, it can be seen that a significant development in the flexural strength of FAGP concrete at 7 days $(3.57 \mathrm{MPa})$, which was $93.70 \%$ of its flexural strength at 28 days. The flexural strength of FAGP and AAS concrete was very similar to the OPC concrete at 28 days, as shown in Table 4.

For the HSC, the average flexural strength of FAGP, AAS and OPC concrete at 7 days was flexural strength at 7 days. The flexural strengths of FAGP, AAS and OPC concrete increased with the increase in the age of concrete. The average flexural strength of FAGP, AAS and OPC concrete at 28 days was $6.42 \mathrm{MPa}, 6.31 \mathrm{MPa}$ and $5.81 \mathrm{MPa}$, respectively. The flexural strength of FAGP, AAS and OPC concrete increased by $5.76 \%, 16.85 \%$ and $27.13 \%$, respectively, at 28 days compared to the flexural strengths at 7 days. The FAGP concrete achieved the highest flexural strength at 7 days (6.07 MPa), which was $94.54 \%$ of its flexural strength at 28 days. The flexural strength of FAGP and AAS concrete was $10.5 \%$ and $8.6 \%$, respectively, higher than the flexural strengths of OPC concrete at 28 days (Table 4). These findings agree with previous studies which reported that FAGP concrete achieved higher flexural strength than OPC concrete for heat cured [34] and ambient cured geopolymer concrete of similar compressive strengths $[8,11,35,36]$. Sarker et al. [37] also reported that AAS concrete had higher flexural strengths than OPC concrete of similar compressive strengths.

\subsection{Stress-strain behaviour under uniaxial tension}

471 The stress-strain behaviour under uniaxial tension of normal strength and high strength FAGP, 472 AAS and OPC concrete are shown in Figs. (6-7). It can be observed that the ascending branches 473 of the stress-strain curves of FAGP, AAS and OPC concrete exhibited similar behaviours up 
to the peak stress. After reaching peak stress, the FAGP, AAS and OPC concrete showed a

475

476

477

478

479

480

481

482

483

484

485

486

487

488

489

490

491

492

493

494

495

496

497

498

brittle failure as soon as they reached the peak stress. The reduction of the cross-sectional area in the middle increased the stresses in the middle of the specimens and induced uniform failure in the middle of the specimens.

\subsubsection{Direct tensile strength}

The direct tensile strength of normal strength FAGP, AAS and OPC concrete are presented in Table 4. The average direct tensile strengths of FAGP, AAS and OPC concrete at 7 days was 2.33 MPa, 2.02 MPa and 1.91 MPa, respectively. The average direct tensile strength of FAGP, AAS and OPC concrete at 28 days was $2.43 \mathrm{MPa}, 2.42 \mathrm{MPa}$ and 2.41 MPa, respectively. The direct tensile strength of FAGP, AAS and OPC concrete increased by $4.29 \%, 19.80 \%$ and $26.18 \%$ at 28 days, respectively, compared to the direct tensile strength at 7 days.

The high strength FAGP, AAS and OPC concrete specimens achieved average direct tensile strengths at 7 days of 3.36 MPa, 2.93 MPa and 2.79 MPa, respectively (Table 4). The direct tensile strength of FAGP, AAS and OPC concrete increased with the increase in the concrete age. The average direct tensile strength of FAGP, AAS and OPC concrete at 28 days was 3.52 $\mathrm{MPa}, 3.52 \mathrm{MPa}$ and $3.51 \mathrm{MPa}$, respectively (Table 4). The direct tensile strength of FAGP, AAS and OPC concrete increased by $4.76 \%, 20.14 \%$ and $25.81 \%$, respectively, at 28 days compared to the direct tensile strength at 7 days.

It was observed that the average direct tensile strength of FAGP, AAS and OPC concrete was less than the average indirect tensile and flexural strength of FAGP, AAS and OPC concrete, respectively. The lower direct tensile strength compared to the indirect tensile and flexural strengths was similar to the observation reported in Swaddiwudhipong et al. [38] for normal 
strength OPC concrete. The average direct tensile strength of normal strength FAGP, AAS and

OPC concrete was found to be $32 \%, 30 \%$ and $31 \%$ less than the average indirect tensile strength

501

502

503

504

505

506

507

508

509

510

511

512

513

514

515

516

517

518

519

520

521

522

523

of FAGP, AAS and OPC concrete at 28 days, respectively. Also, the average direct tensile strength of FAGP, AAS and OPC concrete was found to be $37 \%, 33 \%$ and $36 \%$ less than the average flexural strength of FAGP, AAS and OPC concrete at 28 days, respectively. For the HSC, the average direct tensile strength of FAGP, AAS and OPC concrete was found to be $38 \%, 32 \%$ and $29 \%$ less than the average indirect tensile strength of FAGP, AAS and OPC concrete at 28 days, respectively. Also, the average direct tensile strength of FAGP, AAS and OPC concrete was found to be $45 \%, 44 \%$ and $40 \%$ less than the average flexural strength of FAGP, AAS and OPC concrete at 28 days, respectively.

\subsubsection{Peak stress and corresponding strain}

The peak stress and strain at peak stress of normal strength FAGP, AAS and OPC concrete are presented in Table 6. It can be observed that the FAGP, AAS and OPC concrete specimens achieved peak stresses at 7 days of $2.33 \mathrm{MPa}, 2.02 \mathrm{MPa}$ and 1.91 MPa, respectively. The FAGP concrete achieved higher peak stress than OPC and AAS at 7 days. However, the peak stress of FAGP, AAS and OPC concrete specimens was similar at 28 days. The specimens of FAGP, AAS and OPC concrete achieved peak stresses at 28 days of $2.43 \mathrm{MPa}, 2.42 \mathrm{MPa}$ and 2.41 $\mathrm{MPa}$, respectively. The peak stresses of FAGP, AAS and OPC concrete increased by $4.29 \%$, $19.80 \%$ and $26.18 \%$ at 28 days, respectively. Also, the strain corresponding peak stress of FAGP, AAS and OPC concrete increased by $7.14 \%, 16.67 \%$ and $8.34 \%$, respectively, at 28 days compared to the strain at peak stresses at 7 days.

For the HSC, the peak stress of FAGP, AAS and OPC concrete at 7 days was 3.36 MPa, 2.93 $\mathrm{MPa}$ and 2.79 MPa, respectively. The peak stress of FAGP, AAS and OPC concrete increased 
with time. The FAGP, AAS and OPC concrete achieved peak stresses of $3.52 \mathrm{MPa}, 3.52 \mathrm{MPa}$ and 3.51 MPa at 28 days (Table 6). The peak stresses of FAGP, AAS and OPC concrete increased by $4.76 \%, 20.14 \%$ and $25.81 \%$, respectively, at 28 days compared to the peak stresses at 7 days. Also, the strain corresponding peak stress of FAGP, AAS and OPC concrete increased by $17.64 \%, 12.5 \%$ and $13.34 \%$, respectively, at 28 days compared to the strain at peak stresses at 7 days (Table 6).

\subsubsection{Modulus of elasticity}

The modulus of elasticity of FAGP, AAS and OPC concrete was calculated using the slope of ascending branches of tensile stress-strain curves. The modulus of elasticity of normal strength and high strength FAGP, AAS and OPC concrete are presented in Table 6. For NSC, the modulus of elasticity at 7 days was $16.59 \mathrm{GPa}, 16.20 \mathrm{GPa}$ and $16.23 \mathrm{GPa}$ for the FAGP, AAS and OPC concrete specimens, respectively (Table 6). The modulus of elasticity at 28 days was 16.63 GPa, 16.59 GPa and 17.98 GPa for the FAGP, AAS and OPC concrete specimens, respectively. The modulus of elasticity of FAGP, AAS and OPC concrete increased by $0.24 \%$, $2.41 \%$ and $10.78 \%$ at 28 days, respectively, compared to the modulus of elasticity at 7 days. The OPC concrete achieved $8.12 \%$ and $8.38 \%$ higher modulus of elasticity than FAGP and AAS concrete at 28 days, respectively. The modulus of elasticity of high strength FAGP, AAS and OPC concrete was 19.22 GPa, 18.38 GPa and 18.66 GPa at 7 days, respectively (Table 6). The modulus of elasticity of FAGP, AAS and OPC concrete at 28 days was found to be 19.46 GPa, 19.36 GPa and 20.95 GPa, respectively. The modulus of elasticity of FAGP, AAS and OPC concrete increased by $1.25 \%, 5.33 \%$ and $12.27 \%$ at 28 days, respectively; compared to the modulus of elasticity at 7 days. The OPC specimens achieved $7.65 \%$ and $8.21 \%$ higher modulus of elasticity than FAGP and AAS concrete at 28 days, respectively. 
For the NSC, the experimental stress-strain behaviour in compression of the specimens of FAGP, AAS and OPC concrete at 7 and 28 days are shown in Fig. 8. It was observed that the ascending branch of the stress-strain curves of FAGP, AAS and OPC concrete was almost linear until the peak stress (Fig. 8). After reaching peak stress, the FAGP and AAS concrete showed a more rapid decline in the descending branch of the stress-strain curves and failed in a brittle manner immediately after the peak stress. However, OPC concrete showed a softening decline in the descending branch of the stress-strain curves. The increase in the brittleness of FAGP and AAS concrete was also reported by Atiş et al. [39] and can be attributed to the high micro-cracking in FAGP and AAS concrete [13]. For the HSC, the experimental stress-strain behaviour of specimens of FAGP, AAS and OPC concrete at 7 and 28 days are shown in Fig. 9. As the compressive strength increased, the slope of the ascending and descending branches of the stress-strain curves became steeper (Fig. 9). In addition, the failure was more sudden and explosive rather than continual softening.

\subsubsection{Peak stress and corresponding strain}

The peak stress and strain at peak stress obtained from the stress-strain curve are shown in MPa, 26.88 MPa and 24.81 MPa, respectively (Table 7). The FAGP concrete achieved higher peak stress than AAS and OPC concrete at 7 days. The peak stress for FAGP concrete increased slightly with time, whereas the peak stress of AAS and OPC concrete increased significantly with time. The peak stress of FAGP, AAS and OPC concrete at 28 days was $33.39 \mathrm{MPa}, 34.08$ $\mathrm{MPa}$ and $33.06 \mathrm{MPa}$, respectively. The peak stress of FAGP, AAS and OPC concrete increased by $3.05 \%, 26.78 \%$ and $33.25 \%$, respectively, at 28 days compared to the peak stresses at 7 days. While, the strain corresponding peak stress of FAGP, AAS and OPC concrete increased 
by $1.83 \%, 5.42 \%$ and $2.46 \%$, respectively, at 28 days compared to the strain at peak stress at 7 days (Table 7).

For the HSC, the peak stress of FAGP, AAS and OPC concrete at 7 days was $59.36 \mathrm{MPa}, 52.18$ $\mathrm{MPa}$ and $48.56 \mathrm{MPa}$, respectively. The peak stress of FAGP concrete was higher than AAS and OPC concrete at 7 days. The peak stress of FAGP concrete slightly increased with time, whereas the peak stress of AAS and OPC concrete increased significantly with time. The peak stress of FAGP, AAS and OPC concrete at 28 days was $63.07 \mathrm{MPa}, 64.26 \mathrm{MPa}$ and $63.34 \mathrm{MPa}$ respectively. The peak stress of FAGP, AAS and OPC concrete increased by $6.25 \%, 23.15 \%$ and $30.44 \%$, respectively, at 28 days compared to the peak stresses at 7 days. The strain corresponding to the peak stress of FAGP, AAS and OPC concrete increased by $3.65 \%, 2.55 \%$ and $12.96 \%$, respectively, at 28 days compared to the strain at peak stresses at 7 days (Table 7).

\subsubsection{Modulus of elasticity}

The modulus of elasticity was calculated according to ACI 318-11 [40] as the slope of the tangent of a stress-strain curve drawn from the origin to the stress equals $45 \%$ of the peak stress. The slope of the tangent represents the modulus of elasticity of FAGP, AAS and OPC concrete. The modulus of elasticity of normal strength FAGP, AAS and OPC concrete are presented in Table 7. The modulus of elasticity of FAGP, AAS and OPC concrete at 7 days was $17.34 \mathrm{GPa}$, 16.82 $\mathrm{GPa}$ and $18.78 \mathrm{GPa}$, respectively. The modulus of elasticity increased as the concrete age increased. The modulus of elasticity of FAGP, AAS and OPC concrete at 28 days was 18.05 GPa, 17.95 GPa and 20.20 GPa, respectively. The modulus of elasticity of FAGP, AAS and OPC concrete increased by $4.09 \%, 6.72 \%$ and $7.56 \%$, respectively, at 28 days compared to the modulus of elasticity at 7 days. 
The modulus of elasticity of high strength FAGP, AAS and OPC concrete was $21.35 \mathrm{GPa}$,

601

602

603

604

605

606

607

608

609

610

611

612

613

614

615

616

617

618

619

620

621

622

20.21 GPa and 22.10 GPa, respectively, at 7 days (Table 7). The modulus of elasticity increased as the concrete age increased. The modulus of elasticity of FAGP, AAS and OPC concrete at 28 days was found to be $24.47 \mathrm{GPa}, 23.30 \mathrm{GPa}$ and $27.63 \mathrm{GPa}$, respectively. The modulus of elasticity of FAGP, AAS and OPC concrete increased by $14.61 \%, 15.29 \%$ and $25.02 \%$, respectively, at 28 days compared to the modulus of elasticity at 7 days. As such, the FAGP and AAS concrete had a lower modulus of elasticity than OPC concrete with similar compressive strength. The experimental results indicated that FAGP concrete had about 12$13 \%$ less modulus of elasticity than OPC concrete at 28 days. The AAS concrete had about 13$19 \%$ less modulus of elasticity than OPC concrete at 28 days. A similar observation was reported by Olivia and Nikraz [41] for heat cured fly ash based geopolymer concrete which exhibited a modulus of elasticity of $14.9-28.8 \%$ less than OPC concrete with similar compressive strengths. Hardjito et al. [42] reported that the modulus of elasticity of heat cured fly ash based geopolymer was about $10 \%$ lower than OPC concrete with similar compressive strengths. Yang et al. [25] and Douglas et al. [43] also reported that alkali-activated concrete generally had a lower modulus of elasticity than OPC concrete with similar compressive strengths.

\section{Comparison between calculated and experimental results}

The design standards specified equations to calculate indirect tensile strength, flexural strength and modulus of elasticity from compressive strength of OPC concrete. The equations specified in the ACI 318-14 [32] and AS 3600-2009 [33] for OPC concrete and the equations proposed in the previous studies $[11,42,44,45,46]$ for geopolymer concrete were used to calculate 
623

624

625

626

627

628

629

630

631

632

633

634

635

636

637

638

639

640

641

642

643

644

indirect tensile strength, flexural strength and modulus of elasticity of FAGP and AAS concrete and compared with the experimental results.

\subsection{Indirect tensile strengths}

The ACI 318-14 [32] specified Eq. (1) as the approximate relationship between the indirect tensile strength and the compressive strength.

$$
f_{c t . s p}=0.56 \sqrt{f_{C^{\prime}}} \quad(\mathrm{MPa})
$$

where $f_{c t . s p}$ is indirect tensile strength (MPa) and $f_{C^{\prime}}$ is the specified compressive strength (MPa) at 28 days.

The AS 3600-2009 [33] specified Eq. (2) as the relationship between the indirect tensile strength and compressive strength.

$f_{c t . s p}=0.36 \sqrt{f_{c}^{\prime}}(\mathrm{MPa})$

Sofi et al. [44] proposed Eq. (3) for the relationship between indirect tensile strength and compressive strength of fly ash based geopolymer concrete.

$$
f_{c t . s p}=0.48 \sqrt{f_{C^{\prime}}}(\mathrm{MPa})
$$

Gunasekera et al. [45] proposed Eq. (4) for the relationship between indirect tensile strength and compressive strength of concrete.

$$
f_{c t . s p}=0.45 \sqrt{f_{C^{\prime}}}(\mathrm{MPa})
$$

The relationship between indirect tensile strength and compressive strength of the experimental and calculated values are shown in Fig. 10. It can be seen that the experimental indirect tensile strength of normal strength FAGP and AAS concrete are close to the calculated indirect tensile strength using ACI 318-14 [32] and mostly higher than those calculated using AS 3600-2009 
645 [33], Sofi et al. [44] and Gunasekera et al. [45]. However, the experimental indirect tensile 646 strength for high strength FAGP and AAS concrete were higher than the indirect tensile 647 strength calculated using ACI 318-14 [32], AS 3600-2009 [33], Sofi et al. [44] and Gunasekera 648 et al. [45] (Fig. 10). The results obtained using ACI 318-14 [37] for OPC concrete provided a 649 conservative estimate of normal strength FAGP and AAS concrete. However, the ACI 318-14 650 [32] for OPC concrete did not provide a conservative estimate of high strength FAGP and AAS concrete.

652

653

\subsection{Flexural Strengths}

654 The equations in the ACI 318-14 [32] and AS 3600-2009 [33] for OPC concrete and proposed 655 in previous studies $[11,44,46]$ for geopolymer concrete were used to calculate the flexural 656 strength of FAGP and AAS concrete and compared with the experimental results.

657 The ACI 318-14 [32] recommended Eq. (5) for the relationship between the flexural strength 658 and compressive strength of concrete.

$659 f_{c t . f}=0.62 \sqrt{f_{C^{\prime}}}(\mathrm{MPa})$

660

where $f_{c t . f}$ is the flexural strength (MPa) and $f_{C^{\prime}}$ is the specified compressive strength (MPa)

661 at 28 days.

662

The AS 3600-2009 [33] recommended Eq. (6) for the relationship between the flexural strength

663 and compressive strength of concrete.

$664 f_{c t . f}=0.6 \sqrt{f_{C^{\prime}}}(\mathrm{MPa})$

665 Diaz-Loya et al. [11] suggested Eq. (7) for the relationship between the flexural and 666 compressive strength of geopolymer concrete.

$667 f_{c t . f}=0.69 \sqrt{f_{C^{\prime}}}(\mathrm{MPa})$ 
671

672

673

The relationship between flexural strength and compressive strength of the experimental and calculated values are drawn in Fig. 11. Figure 11 indicates that the experimental flexural strength of normal strength FAGP and AAS concrete are comparable to those calculated using ACI 318-14 [32] and AS 3600-2009 [33]. However, the experimental flexural strength of normal strength FAGP and AAS concrete are lower than those calculated using Diaz-Loya et al. [11] and Nath and Sarker [46] for geopolymer concrete. The experimental flexural strength of high strength FAGP and AAS concrete are higher than those calculated using ACI 318-14 [32], AS 3600-2009 [33] and Diaz-Loya et al. [11] and lower than those calculated using Nath and Sarker [46]. This means that ACI 318-14 [32] and AS 3600-2009 [33] for OPC provided a conservative estimate of normal strength FAGP and AAS concrete in terms of flexural strength. However, the ACI 318-14 [32] and AS 3600-2009 [33] for OPC concrete did not provide a conservative estimate of high strength FAGP and AAS concrete.

\subsection{Modulus of elasticity}

The equations specified in the ACI 318-14 [32] and AS 3600-2009 [33] for OPC concrete were used to calculate modulus of elasticity of FAGP and AAS concrete and compared with the experimental results. Also, the equations proposed in Hardjito et al. [42] and Diaz-Loya et al. [11] for geopolymer concrete were used to calculate the modulus of elasticity of FAGP and AAS concrete and compared with the experimental results.

The ACI 318-14 [32] specified Eq. (9) for the modulus of elasticity of OPC concrete. 
693 where $E_{C}$ is the modulus of elasticity, $\rho$ is the density of concrete $\left(\mathrm{kg} / \mathrm{m}^{3}\right)$ and $f_{C^{\prime}}$ is compressive strength at 28 days.

695

The AS 3600-2009 [33] specified Eq. (10) for the modulus of elasticity of OPC concrete.

696

$E_{C}=\left(\rho^{1.5}\right) \times\left(0.024 \sqrt{f_{C^{\prime}}}+0.12\right)$ when $f_{C^{\prime}}>40 \mathrm{MPa}$

697

698

699

700

701

702

703

704

705

706

707

708

709

710

711

712

713

714

According to AS 3600-2009 [33], the modulus of elasticity can be calculated using a similar equation proposed in the ACI 318-14 [32] for OPC concrete of compressive strength less than $40 \mathrm{MPa}$.

Hardjito et al. [42] proposed Eq. (11) for the modulus of elasticity of geopolymer concrete.

$$
E_{C}=2707 \sqrt{f_{C^{\prime}}}+5300
$$

Diaz-Loya et al. [11] proposed Eq. (12) for the modulus of elasticity of geopolymer concrete

$$
E_{C}=0.037 \times \rho^{1.5} \times \sqrt{f_{C^{\prime}}}
$$

The calculated and experimental results of the modulus of elasticity of FAGP and AAS concrete are shown in Fig. 12. The results obtained from the ACI 318-14 [32], AS 3600-2009 [33] and Diaz-Loya et al. [11] overestimated the experimental results of normal strength and high strength FAGP and AAS concrete (Fig. 12). Similar observations were reported in the previous studies conducted on the comparison between calculated and experimental modulus of elasticity. Yost et al. [47] reported that the modulus of elasticity of FAGP concrete was 11$16 \%$ less than the calculated modulus of elasticity using ACI 318-14 [32]. Yang et al. [25] found that modulus of elasticity of AAS concrete was $12-15 \%$ lower than the values calculated using ACI 318-14 [32]. The calculated modulus of elasticity using ACI 318-14 [32] and AS 3600-2009 [33] for OPC concrete did not provide a conservative estimate of normal and high strength FAGP and AAS concrete in terms of modulus of elasticity. However, the results 
obtained using Hardjito et al. [42] was very close to those obtained from experimental results.

Therefore, the modulus of elasticity for normal strength and high strength FAGP and AAS concrete can be reasonably estimated using the equation proposed by Hardjito et al. [42].

\section{Conclusions}

720

This paper compares the engineering properties of normal strength and high strength FAGP and AAS concrete with OPC concrete. The following conclusions are drawn from the test results.

1. The average dry density and ultrasonic pulse velocity of FAGP and AAS concrete were lower than those of OPC concrete. This finding was confirmed by SEM analyses. The SEM images showed that at 28 days, FAGP and AAS concrete were less dense and less compacted with less homogeneous microstructures compared to OPC concrete.

2. The normal strength FAGP, AAS and OPC concrete have comparable indirect tensile, flexural and direct tensile strengths. However, the indirect tensile, flexural strength and direct tensile strength of high strength (compressive strength of about $65 \mathrm{MPa}$ ) FAGP and AAS concrete were higher than those of high strength OPC concrete.

3. The equations recommended in ACI 318-14 [32] for OPC concrete can be used for the conservative prediction of the indirect tensile strength of normal strength (compressive strength of about $35 \mathrm{MPa}$ ) FAGP and AAS concrete. However, the current ACI 318-14 [32] for OPC concrete does not provide a conservative estimate of the indirect tensile strength of high strength (compressive strength of about $65 \mathrm{MPa}$ ) FAGP and AAS concrete. The equations recommended in ACI 318-14 [32] and AS 3600-2009 [33] can be used for conservative prediction of the flexural strength of normal strength concrete (compressive strength of about $35 \mathrm{MPa}$ ) FAGP and AAS concrete. However, the equations recommended in ACI 318-14 [32] 
and AS 3600-2009 [33] does not provide a conservative estimate of the flexural strength of high strength (compressive strength of about $65 \mathrm{MPa}$ ) FAGP and AAS concrete.

4. The modulus of elasticity of normal strength and high strength FAGP and AAS concrete under uniaxial tension was about $7-8 \%$ and $8-9 \%$ less than the modulus of elasticity of OPC with the similar compressive strengths at 28 days. The modulus of elasticity of normal strength and high strength FAGP and AAS concrete under compression was about 12-13\% and 13-19\% less than the modulus of elasticity of OPC with a similar compressive strength at 28 days.

5. The modulus of elasticity of normal strength and high strength FAGP and AAS concrete calculated using ACI 318-14 [32], AS 3600-2009 [33] and Diaz-Loya et al. [11] was higher than the experimental modulus of elasticity. However, the modulus of elasticity of normal strength and high strength FAGP and AAS concrete can be closely estimated reasonably using equation recommended in Hardjito et al. [42].

751

752

\section{Acknowledgements}

753 The authors gratefully acknowledge the contribution of the technical staff at the High Bay

754 Laboratories of the University of Wollongong in carrying out the experimental work. The 755 authors also express thanks to the Australian Slag Association for providing aluminosilicate materials. The first author also thanks to the Iraqi government and UOW for the award of $\mathrm{PhD}$ scholarship. 


\section{References}

759 1. Turner, L. K., \& Collins, F. G. (2013). Carbon dioxide equivalent (CO 2-e) emissions: a comparison between geopolymer and OPC cement concrete. Construction and Building Materials, 43, 125-130.

2. Gartner, E. (2004). Industrially interesting approaches to "low-CO 2" cements. Cement and Concrete research, 34(9), 1489-1498.

764

3. Duan, P., Yan, C., Zhou, W., Luo, W., \& Shen, C. (2015). An investigation of the microstructure and durability of a fluidized bed fly ash-metakaolin geopolymer after heat and acid exposure. Materials \& Design, 74,125-137.

4. Wallah, S. E. (2010). Creep behaviour of fly ash-based geopolymer concrete. Civil Engineering Dimension, 12(2), 73-78.

5. Ryu, G. S., Lee, Y. B., Koh, K. T., \& Chung, Y. S. (2013). The mechanical properties of fly ash-based geopolymer concrete with alkaline activators. Construction and Building Materials, 47, 409-418.

6. Akçaözoğlu, S., \& Atiş, C. D. (2011). Effect of granulated blast furnace slag and fly ash addition on the strength properties of lightweight mortars containing waste PET aggregates. Construction and Building Materials, 25(10), 4052-4058.

7. Farhan, N. A., Sheikh, M. N., \& Hadi, M. N. S. (2018). Experimental investigation on properties of alkali-activated fly ash concrete. ACI Materials Journal, 103(2), 106. ash-based geopolymer concrete. 
10. Neupane, K., Baweja, D., Shrestha, R., Chalmers, D., \& Sleep, P. (2014). Mechanical properties of geopolymer concrete: Applicability of relationships defined by AS 3600. Concrete in Australia, 40 (1), 50-56.

11. Ivan Diaz-Loya, E., Allouche, E. N., \& Vaidya, S. (2011). Mechanical Properties of Fly-Ash-Based Geopolymer Concrete. ACI Materials Journal, 108(3).

12. Bernal, S. A., de Gutiérrez, R. M., Pedraza, A. L., Provis, J. L., Rodriguez, E. D., \& Delvasto S. (2011). Effect of binder content on the performance of alkali-activated slag concretes. Cement and Concrete Research, 41(1), 1-8.

13. Lee, N. K., \& Lee, H. K. (2013). Setting and mechanical properties of alkali-activated fly ash/slag concrete manufactured at room temperature. Construction and Building Materials, 47, 1201-1209.

14. Chi, M. (2012). Effects of dosage of alkali-activated solution and curing conditions on the properties and durability of alkali-activated slag concrete. Construction and Building Materials, 35, 240-245.

15. American Society for Testing Materials. Standard Specification for Coal Fly Ash and Raw or Calcined Natural Pozzolan for use as a Mineral Admixture in Portland Cement Concrete. ASTM C618; 2012.

16. AS 1012.3.1, 1998a. Methods of testing concrete - method 9: determination of properties related to the consistency of concrete - slump test. Australian Standard, Sydney, NSW, Australia.

17. AS 1012.12, 1998b. Methods of testing concrete - Determination of mass per unit volume of hardened concrete - Water displacement method. Australian Standard, Sydney, NSW, Australia.

18. ASTM C597, 2009. Standard Test Method for Pulse Velocity Through Concrete. ASTM International. 
19. AS 1012.9, 1999. Methods of testing concrete; Method 9: Determination of the compressive strength of concrete specimens. Australian Standard, Sydney, NSW, Australia.

20. AS 1012.10, 2000a. Methods of testing concrete - Determination of indirect tensile strength of concrete cylinders Brasil or splitting test). Australian Standard, Sydney, R2014, NSW, Australia.

21. AS 1012.11, 2000b. Methods of testing concrete - Determination of the modulus of rupture. Australian Standard, Sydney, R2014, NSW, Australia.

22. Alhussainy, F., Hasan, H. A., Rogic, S., Sheikh, M. N., \& Hadi M. N. S. (2016). Direct tensile testing of self-compacting concrete. Construction and Building Materials, 112, 903-906.

23. AS 1012.17, 2014. Methods of testing concrete - Determination of the static chord modulus of elasticity and Poisson's ratio of concrete specimens. Australian Standard, Sydney, NSW, Australia.

24. Diaz, E. I., Allouche, E. N., \& Eklund, S. (2010). Factors affecting the suitability of fly ash as source material for geopolymers. Fuel, 89(5), 992-996.

25. Yang, K. H., Song, J. K., Lee, K. S., \& Ashour, A. F. (2009). Flow and Compressive Strength of Alkali-Activated Mortars. ACI Materials Journal, 106(1), 50-58.

26. Collins, F. G., \& Sanjayan, J. G. (1999). Workability and mechanical properties of alkali activated slag concrete. Cement and concrete research, 29(3), 455-458.

27. Atiş, C. D., \& Karahan, O. (2009). Properties of steel fiber reinforced fly ash concrete. Construction and Building Materials, 23(1), 392-399.

28. Adam, A. (2009). Strength and durability properties of alkali activated slag and fly ashbased geopolymer concrete, Doctor of Philosophy (PhD), Civil, Environmental and Chemical Engineering, RMIT University. 
29. Deb, P. S., Nath, P., \& Sarker, P. K. (2015). Use of OPC to improve setting and early strength properties of low calcium fly ash geopolymer concrete cured at room temperature. Cement and concrete research, 55, 205-214.

30. IAEA. (2002). Guide book on Non-Destructive Testing of concrete structures. Training Courses Series no. 17. Vienna, Austria: International Atomic Energy Agency.

31. Bernal, S., De Gutierrez, R., Delvasto, S., \& Rodriguez, E. (2010). Performance of an alkali-activated slag concrete reinforced with steel fibers. Construction and building Materials, 24(2), 208-214.

32. ACI 318 (2014). American Concrete Institute. State-of-the-art report on high-strength concrete.

33. AS 3600. (2009) Standard Australia. Concrete structures.

34. Hardjito, D., Wallah, S. E., Sumajouw, D. M., \& Rangan, B. V. (2004). On the development of fly ash-based geopolymer concrete. Materials Journal, 101(6), 467472.

35. Deb, P. S., Nath, P., \& Sarker, P. K. (2014). The effects of ground granulated blastfurnace slag blending with fly ash and activator content on the workability and strength properties of geopolymer concrete cured at ambient temperature. Materials \& Design, 62, 32- 39.

36. Raijiwala, D. B., \& Patil, H. S. (2011). Geopolymer concrete: A concrete of the next decade. Concrete Solutions, 287.

37. Sarker, P. K., Haque, R., \& Ramgolam, K. V. (2013). Fracture behaviour of heat cured fly ash based geopolymer concrete. Materials \& Design, 44, 580-586.

38. Swaddiwudhipong, S., Lu, H. R., \& Wee, T. H. (2003). Direct tension test and tensile strain capacity of concrete at early age. Cement and concrete research, 33(12), 20772084. 
39. Atiş, C. D., Bilim, C., Çelik, Ö., \& Karahan, O. (2009). Influence of activator on the strength and drying shrinkage of alkali-activated slag mortar. Construction and building materials, 23(1), 548-555.

40. ACI 318. (2011). American Concrete Institute. Building Code Requirements for Structural Concrete and Commentary.

41. Olivia, M., \& Nikraz, H. (2012). Properties of fly ash geopolymer concrete designed by Taguchi method. Materials \& Design, 36, 191-198.

42. Hardjito, D., Wallah, S. E., Sumajouw, D. M. J., \& Rangan, B. V. (2004). The stressstrain behaviour of fly ash-based geopolymer concrete. Development in Mechanics of Structures and Material, 831-834.

43. Douglas, E., Bilodeau, A, \& Malhotra, V. M. (1992). Properties and durability of alkaliactivated slag concrete. Materials Journal, 89(5), 509-516.

44. Sofi, M., Van Deventer, J. S. J., Mendis, P. A., \& Lukey, G. C. (2007). Engineering properties of inorganic polymer concretes (IPCs). Cement and Concrete Research, 37(2), 251-257.

45. Gunasekera, C., Setunge, S., \& Law, D. W. (2017). Correlations between Mechanical Properties of Low-Calcium Fly Ash Geopolymer Concretes. Journal of Materials in Civil Engineering, 29(9), 04017111.

46. Nath, P., \& Sarker, P. K. (2017). Flexural strength and elastic modulus of ambientcured blended low-calcium fly ash geopolymer concrete. Construction and Building Materials, 130, 22-31.

47. Yost, J. R., Radlińska, A., Ernst, S., Salera, M. (2013). Structural behavior of alkali activated fly ash concrete. Part 1: mixture design, material properties and sample fabrication. Materials and structures; 46(3): 435-447. 
883 Table 1 The chemical composition FA and GGBS.

884 Table 2 Chemical composition of cement.

885 Table 3 Mix proportion of FAGP, AAS and OPC concrete.

886 Table 4 Engineering properties of FAGP, AAS and OPC concrete at 7 and 28 days.

887 Table 5 Classification of the quality of concrete based on ultrasonic pulse velocity [30].

888 Table 6 Experimental results of the peak stress, strain at peak stress and modulus of elasticity 889 of the tested specimens under uniaxial tension.

890 Table 7 Experimental results of the peak stress, strain at peak stress and modulus of elasticity 891 of the tested specimens under compression. 
894 Fig. 1. Preparation and failure for: (a) FAGP concrete and (b) AAS concrete.

895

Fig. 2. SEM images for (a) FA, (b) GGBS and (c) OPC binder.

896

Fig. 3. SEM images of FAGP concrete: (a) Normal strength concrete and (b) High strength

897 concrete.

898

Fig. 4. SEM images of AAS concrete: (a) Normal strength concrete and (b) High strength

899 concrete.

900

Fig. 5. SEM images of OPC concrete: (a) Normal strength concrete and (b) High strength

901 concrete.

902

Fig. 6. Typical stress-strain behaviour under uniaxial tension for specimens of design

903 compressive strength of $35 \mathrm{MPa}$ : (a) at 7 days and (b) at 28 days.

904

Fig. 7. Typical stress-strain behaviour under uniaxial tension for specimens of design

905 compressive strength of $65 \mathrm{MPa}$ : (a) at 7 days and (b) at 28 days.

906

Fig. 8. Typical stress-strain behaviour under compression for specimens of design

907 compressive strength of $35 \mathrm{MPa}$ : (a) at 7 days and (b) at 28 days.

908

Fig. 9. Typical stress-strain behaviour under compression for specimens of design

909 compressive strength of $65 \mathrm{MPa}$ : (a) at 7 days and (b) at 28 days.

910

Fig. 10. Indirect tensile strength versus compressive strength: (a) FAGP concrete and (b)

911 AAS concrete.

912 Fig. 11. Flexural strength versus compressive strength: (a) FAGP concrete and (b) AAS concrete.

914 Fig. 12. Modulus of elasticity versus compressive strength: (a) FAGP concrete and (b) AAS 915 concrete. 
919 The chemical composition FA and GGBS.

\begin{tabular}{lcc}
\hline Composition (mass) & \multicolumn{2}{c}{ Mass content (\%) } \\
\cline { 2 - 3 } & FA & GGBS \\
\hline $\mathrm{SiO}_{2}$ & 62.2 & 32.4 \\
\hline $\mathrm{Al}_{2} \mathrm{O}_{3}$ & 27.5 & 14.96 \\
\hline $\mathrm{Fe}_{2} \mathrm{O}_{3}$ & 3.92 & 0.83 \\
\hline $\mathrm{CaO}$ & 2.27 & 40.70 \\
\hline $\mathrm{MgO}$ & 1.05 & 5.99 \\
\hline $\mathrm{K}_{2} \mathrm{O}$ & 1.24 & 0.29 \\
\hline $\mathrm{Na}_{2} \mathrm{O}$ & 0.52 & 0.42 \\
\hline $\mathrm{TiO}_{2}$ & 0.16 & 0.84 \\
\hline $\mathrm{P}_{2} \mathrm{O}_{5}$ & 0.30 & 0.38 \\
\hline $\mathrm{Mn}_{2} \mathrm{O}_{3}$ & 0.09 & 0.40 \\
\hline $\mathrm{SO}_{3}$ & 0.08 & 2.74 \\
\hline $\mathrm{Loss}_{3}$ on ignition & 0.89 & NA \\
\hline
\end{tabular}

920

921

922

923

924

925

926

927

928

929

930

931 
932 Table 2

933 Chemical composition of cement.

\begin{tabular}{ll}
\hline Composition (mass) & Mass content (\%) \\
\hline Portland Cement Clinker & $<97$ \\
\hline Gypsum $\left(\mathrm{CaSO}_{4} 2 \mathrm{H}_{2} \mathrm{O}\right)$ & $2-5$ \\
\hline Limestone $\left(\mathrm{CaCO}_{3}\right)$ & $0-7.5$ \\
\hline Calcium Oxide $(\mathrm{CaO})$ & $0-3$ \\
\hline Hexavalent Chromium $\mathrm{Cr}(\mathrm{VI})$ & $<20 \mathrm{ppm}$ \\
\hline Crystalline Silica (Quartz) & $<1$ \\
\hline
\end{tabular}

934

935

936

937

938

939

940

941

942

943

944

945

946

947

948

949

950 
Table 3

952 Mix proportion of FAGP, AAS and OPC concrete.

Concrete mix Normal strength concrete

High strength concrete (NSC) (HSC)

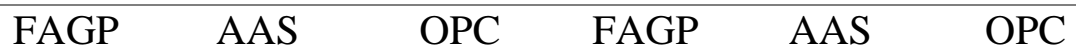

\begin{tabular}{|c|c|c|c|c|c|c|}
\hline Cement $\left(\mathrm{kg} / \mathrm{m}^{3}\right)$ & - & - & 350 & - & - & 461 \\
\hline GGBS $\left(\mathrm{kg} / \mathrm{m}^{3}\right)$ & - & 400 & - & - & 450 & - \\
\hline $\mathrm{FA}\left(\mathrm{kg} / \mathrm{m}^{3}\right)$ & 410 & - & - & 480 & - & 29 \\
\hline Alkaline activator/Binder & 0.45 & 0.45 & - & 0.35 & 0.35 & - \\
\hline Fine aggregate $\left(\mathrm{kg} / \mathrm{m}^{3}\right)$ & 627 & 636 & 760 & 606 & 625 & 650 \\
\hline Coarse aggregate $\left(\mathrm{kg} / \mathrm{m}^{3}\right)$ & 1164 & 1169 & 1138 & 1140 & 1154 & 1150 \\
\hline $\mathrm{Na}_{2} \mathrm{SiO}_{3} / \mathrm{NaOH}$ & 2 & 2.5 & - & 2 & 2.5 & - \\
\hline $\mathrm{Na}_{2} \mathrm{SiO}_{3}\left(\mathrm{~kg} / \mathrm{m}^{3}\right)$ & 123 & 128 & - & 112 & 106 & - \\
\hline $\mathrm{NaOH}\left(\mathrm{kg} / \mathrm{m}^{3}\right)$ & 61.5 & 52 & - & 56 & 53 & - \\
\hline $\mathrm{NaOH}$ (moles/liter) & 12 & 12 & - & 14 & 14 & - \\
\hline Water $\left(\mathrm{kg} / \mathrm{m}^{3}\right)$ & 45 & 48 & 182 & 35 & 40 & 148 \\
\hline Superplasticizer $\left(\mathrm{kg} / \mathrm{m}^{3}\right)$ & 22.5 & 20 & 8 & 17.5 & 12.5 & 6.5 \\
\hline
\end{tabular}

953

954

955 


\section{Table 4}

957 Engineering properties of FAGP, AAS and OPC concrete at 7 and 28 days.

958

\begin{tabular}{|c|c|c|c|c|c|c|c|c|c|c|c|c|c|}
\hline \multirow{2}{*}{$\begin{array}{l}\text { Concrete } \\
\text { Mix }\end{array}$} & \multirow{2}{*}{$\begin{array}{c}\text { Design } \\
\text { compressive } \\
\text { strength } \\
(\mathrm{MPa}) \\
\text { at } 28 \text { days } \\
\end{array}$} & \multicolumn{2}{|c|}{$\begin{array}{l}\text { Dry density } \\
\left(\mathrm{kg} / \mathrm{m}^{3}\right)\end{array}$} & \multicolumn{2}{|c|}{$\begin{array}{l}\text { Ultrasonic pulse } \\
\text { velocity }(\mathrm{km} / \mathrm{s})\end{array}$} & \multicolumn{2}{|c|}{$\begin{array}{l}\text { Compressive } \\
\text { strength }(\mathrm{MPa})\end{array}$} & \multicolumn{2}{|c|}{$\begin{array}{l}\text { Indirect tensile } \\
\text { strength }(\mathrm{MPa})\end{array}$} & \multicolumn{2}{|c|}{$\begin{array}{l}\text { Flexural strength } \\
(\mathrm{MPa})\end{array}$} & \multicolumn{2}{|c|}{$\begin{array}{l}\text { Direct tensile } \\
\text { strength }(\mathrm{MPa})\end{array}$} \\
\hline & & 7 days & 28 days & 7 days & 28 days & 7 days & 28 days & 7 days & 28 days & 7 days & 28 days & 7 days & 28 days \\
\hline FAGP-35 & & 2373 & 2378 & 3.14 & 3.20 & 33.90 & 35.91 & 3.37 & 3.58 & 3.57 & 3.81 & 2.33 & 2.43 \\
\hline AAS-35 & 35 & 2389 & 2403 & 3.18 & 3.31 & 29.03 & 36.44 & 2.93 & 3.55 & 3.21 & 3.79 & 2.02 & 2.42 \\
\hline OPC-35 & & 2368 & 2415 & 3.30 & 3.52 & 26.51 & 35.82 & 2.66 & 3.51 & 3.06 & 3.78 & 1.91 & 2.41 \\
\hline FAGP-65 & & 2381 & 2384 & 3.82 & 3.93 & 61.71 & 65.28 & 5.32 & 5.73 & 6.07 & 6.42 & 3.36 & 3.52 \\
\hline AAS-65 & 65 & 2420 & 2432 & 3.78 & 3.98 & 53.68 & 66.12 & 4.49 & 5.23 & 5.40 & 6.31 & 2.93 & 3.52 \\
\hline OPC-65 & & 2401 & 2443 & 3.87 & 4.15 & 50.73 & 66.69 & 3.78 & 4.94 & 4.57 & 5.81 & 2.79 & 3.51 \\
\hline
\end{tabular}


Table 5

960 Classification of the quality of concrete based on ultrasonic pulse velocity.

Longitudinal pulse velocity $(\mathrm{km} / \mathrm{s}) \quad$ Quality of concrete

\begin{tabular}{ll}
\hline$>4.5$ & Excellent \\
\hline $3.5-4.5$ & good \\
\hline $3.0-3.5$ & medium \\
\hline $2.0-3.0$ & Poor \\
\hline$<2.0$ & Very poor \\
\hline
\end{tabular}

961

962

963

964

965

966

967

968

969

970

971

972

973

974

975

976

977 
979 Experimental results of the peak stress, strain at peak stress, and modulus of elasticity of the 980 tested specimens under uniaxial tension.

\begin{tabular}{lllllll}
\hline \multirow{2}{*}{ Concrete Mix } & \multicolumn{2}{c}{$\begin{array}{l}\text { Average peak stress } \\
(\mathrm{MPa})\end{array}$} & \multicolumn{2}{c}{$\begin{array}{c}\text { Average strain at } \\
\text { peak stress } * 10^{-3}\end{array}$} & \multicolumn{2}{c}{$\begin{array}{c}\text { Average modulus of } \\
\text { elastity }(\mathrm{GPa})\end{array}$} \\
\cline { 2 - 7 } 7 days & 28 days & 7 days & 28 days & 7 days & 28 days \\
\hline FAGP-35 & 2.33 & 2.43 & 0.14 & 0.15 & 16.59 & 16.63 \\
\hline AAS-35 & 2.02 & 2.42 & 0.12 & 0.14 & 16.20 & 16.59 \\
\hline OPC-35 & 1.91 & 2.41 & 0.12 & 0.13 & 16.23 & 17.98 \\
\hline FAGP-65 & 3.36 & 3.52 & 0.17 & 0.20 & 19.22 & 19.46 \\
\hline AAS-65 & 2.93 & 3.52 & 0.16 & 0.18 & 18.38 & 19.36 \\
\hline OPC-65 & 2.79 & 3.51 & 0.15 & 0.17 & 18.66 & 20.95 \\
\hline
\end{tabular}

981

982

983

984

985

986

987

988

989

990

991

992

993

994

995

996 
Table 7

998 Experimental results of peak stress, strain at peak stress, and the modulus of elasticity of 999 specimens tested under compression.

\begin{tabular}{lllllll}
\hline \multirow{2}{*}{ Concrete Mix } & \multicolumn{2}{c}{ Average peak stress } & \multicolumn{2}{c}{$\begin{array}{c}\text { Average strain at } \\
\text { peak stress }\end{array}$} & \multicolumn{2}{c}{$\begin{array}{c}\text { Average modulus of } \\
\text { elasticity }(\mathrm{GPa})\end{array}$} \\
\cline { 2 - 7 } & 7 days & 28 days & 7 days & 28 days & 7 days & 28 days \\
\hline FAGP-35 & 32.40 & 33.39 & 0.00219 & 0.00223 & 17.34 & 18.05 \\
\hline AAS-35 & 26.88 & 34.08 & 0.00203 & 0.00214 & 16.82 & 17.95 \\
\hline OPC-35 & 24.81 & 33.06 & 0.00203 & 0.00208 & 18.78 & 20.20 \\
\hline FAGP-65 & 59.36 & 63.07 & 0.00301 & 0.00312 & 21.35 & 24.47 \\
\hline AAS-65 & 52.18 & 64.26 & 0.00275 & 0.00282 & 20.21 & 23.30 \\
\hline OPC-65 & 48.56 & 63.34 & 0.00216 & 0.00244 & 22.10 & 27.63 \\
\hline
\end{tabular}

1000

1001

1002

1003

1004

1005

1006

1007

1008

1009

1010

1011

1012

1013

1014 


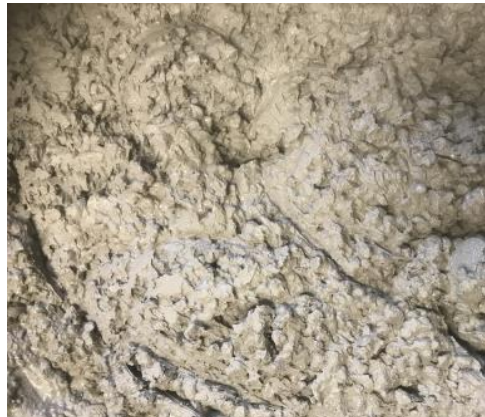

Fresh concrete
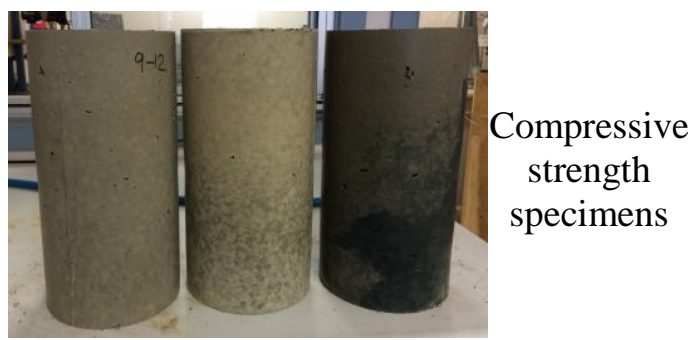

1023

1024

1025

1026

1027

1028

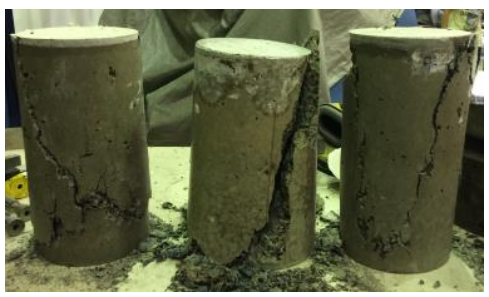

Failure mode

(b) FAGP
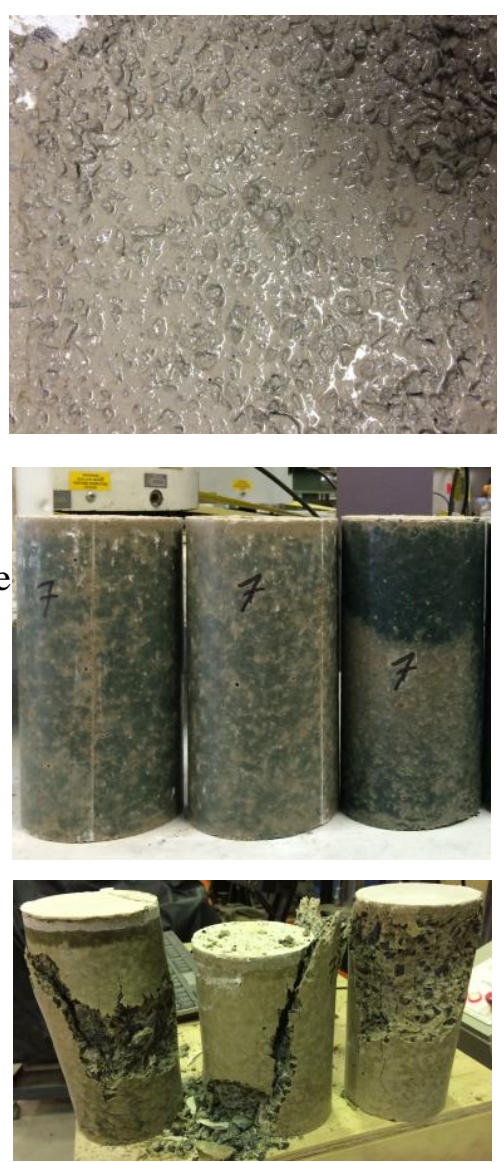

(a) AAS

Fig.1. Preparation and failure for: (a) FAGP concrete and (b) AAS concrete.

1029

1030

1031

1032

1033

1034 


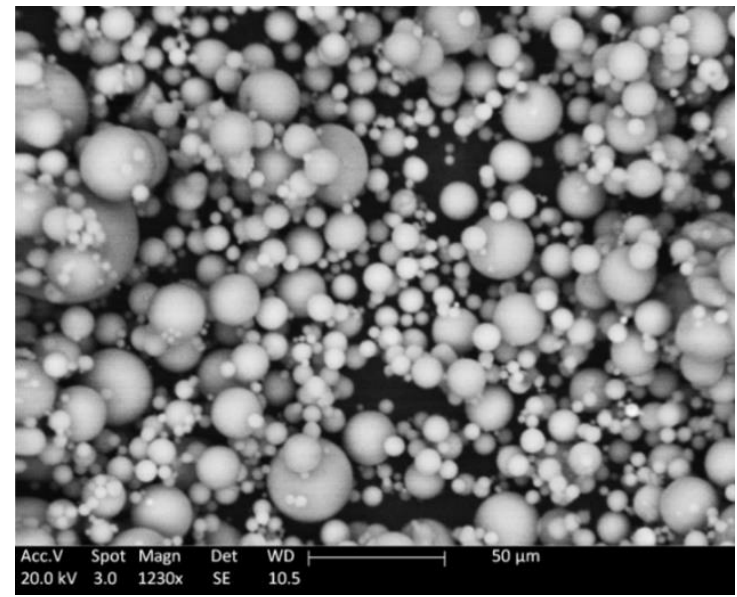

(a) FA

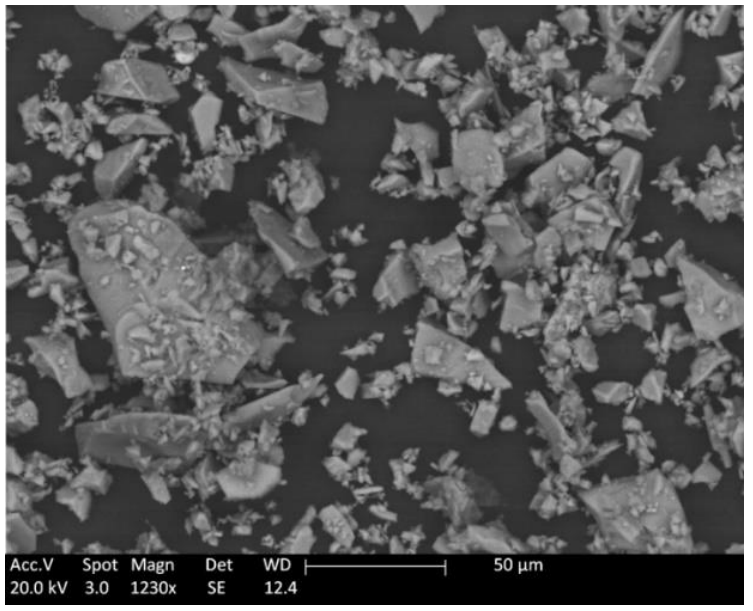

(b) GGBS

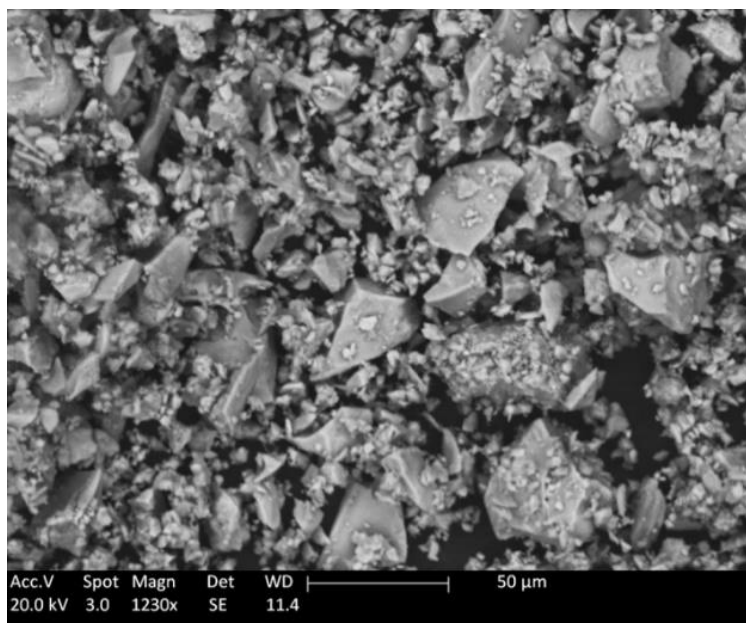

(c) OPC

1041

Fig. 2. SEM images for (a) FA, (b) GGBS and (c) OPC binder. 

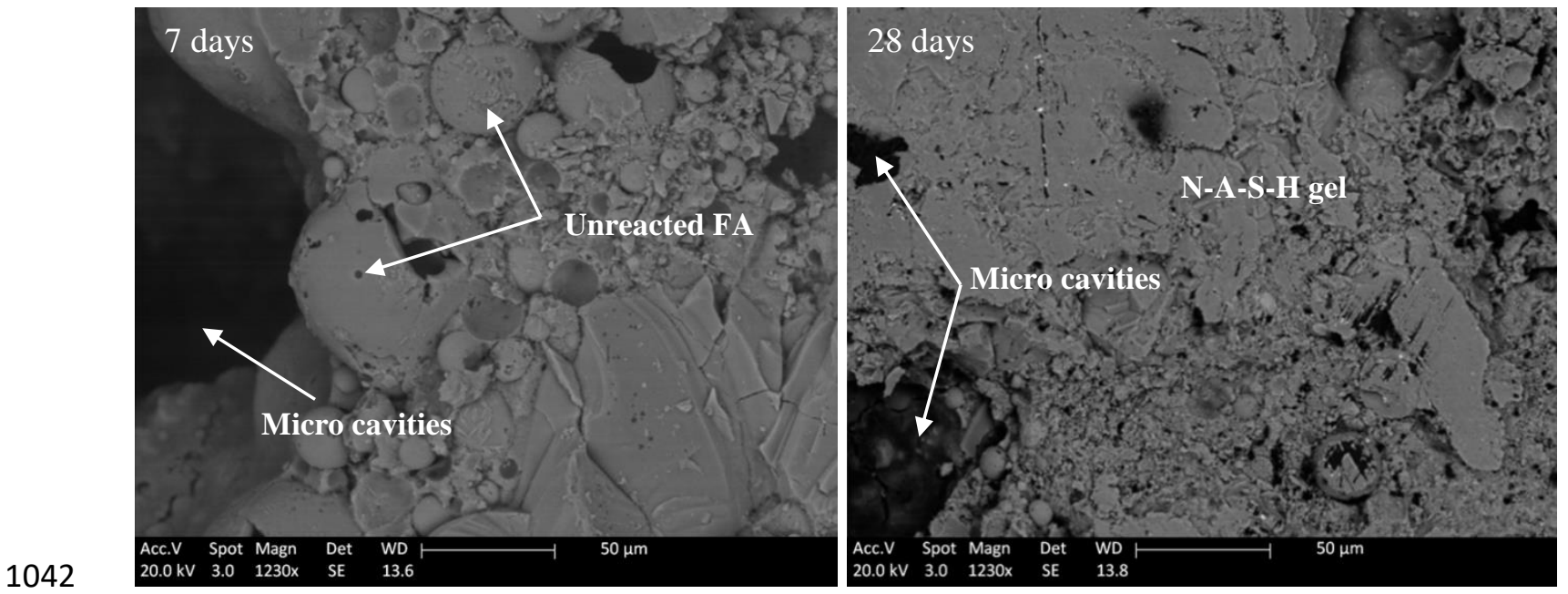

1043

(a)

1044
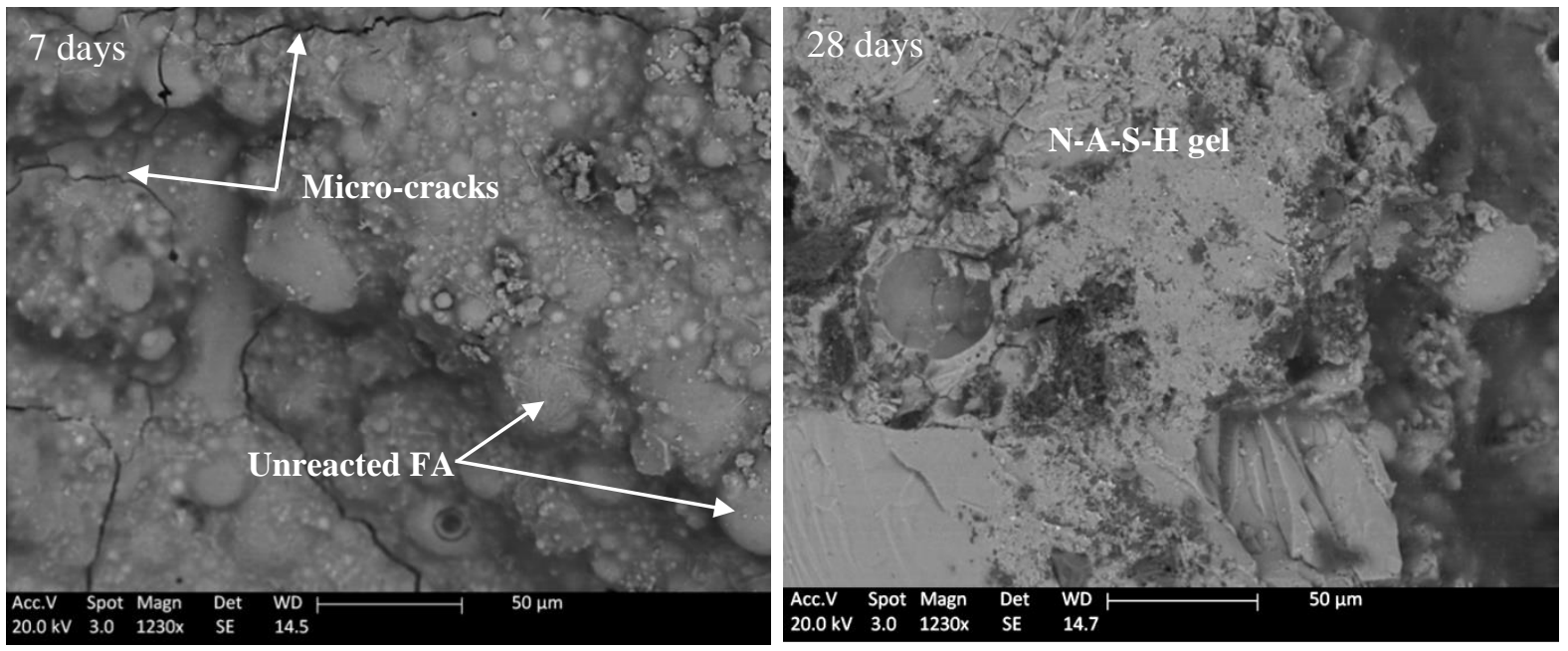

1046

(b)

Fig. 3. SEM images of FAGP concrete: (a) Normal strength concrete and (b) High strength concrete. 


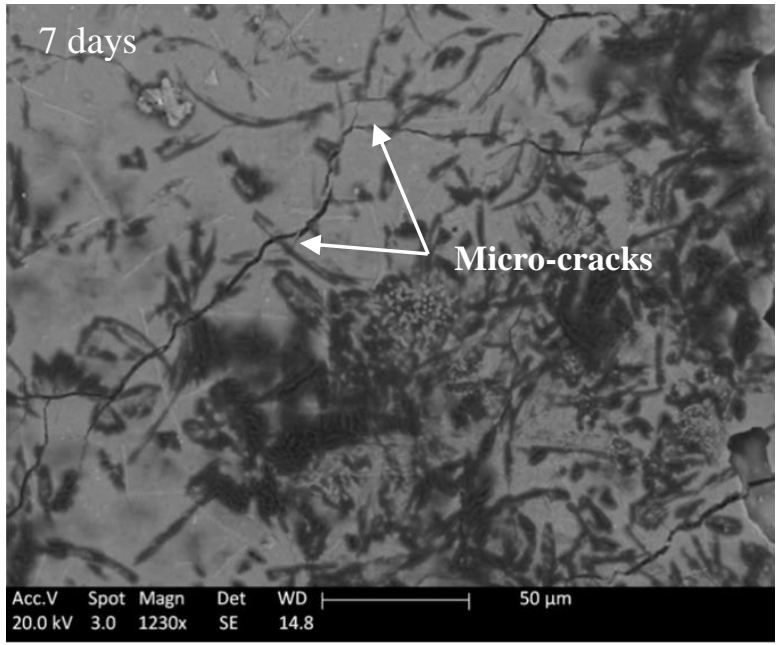

$20.0 \mathrm{kV} \quad 3.0$ 1230x SE 14.8

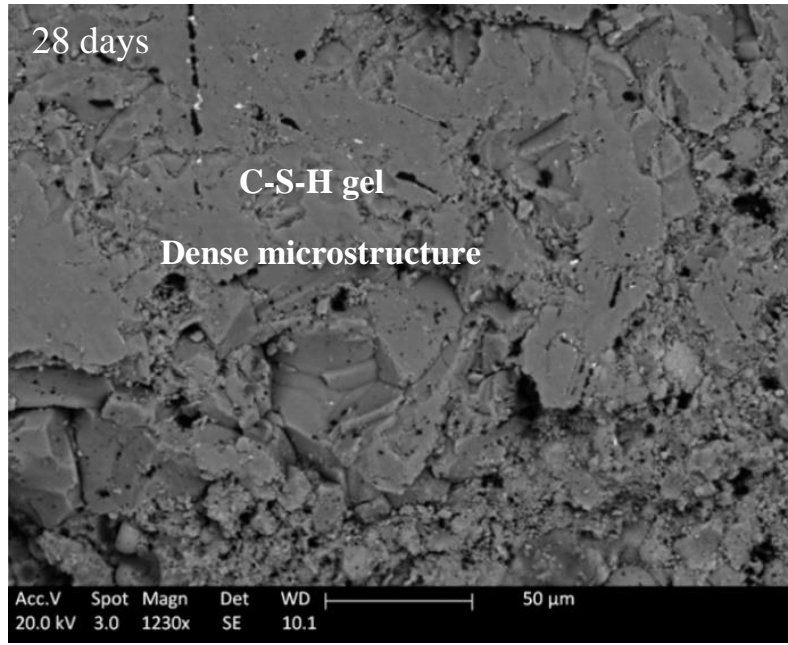

(a)

1055

1056

1057

1058

1059

1060

1061

1062

1063
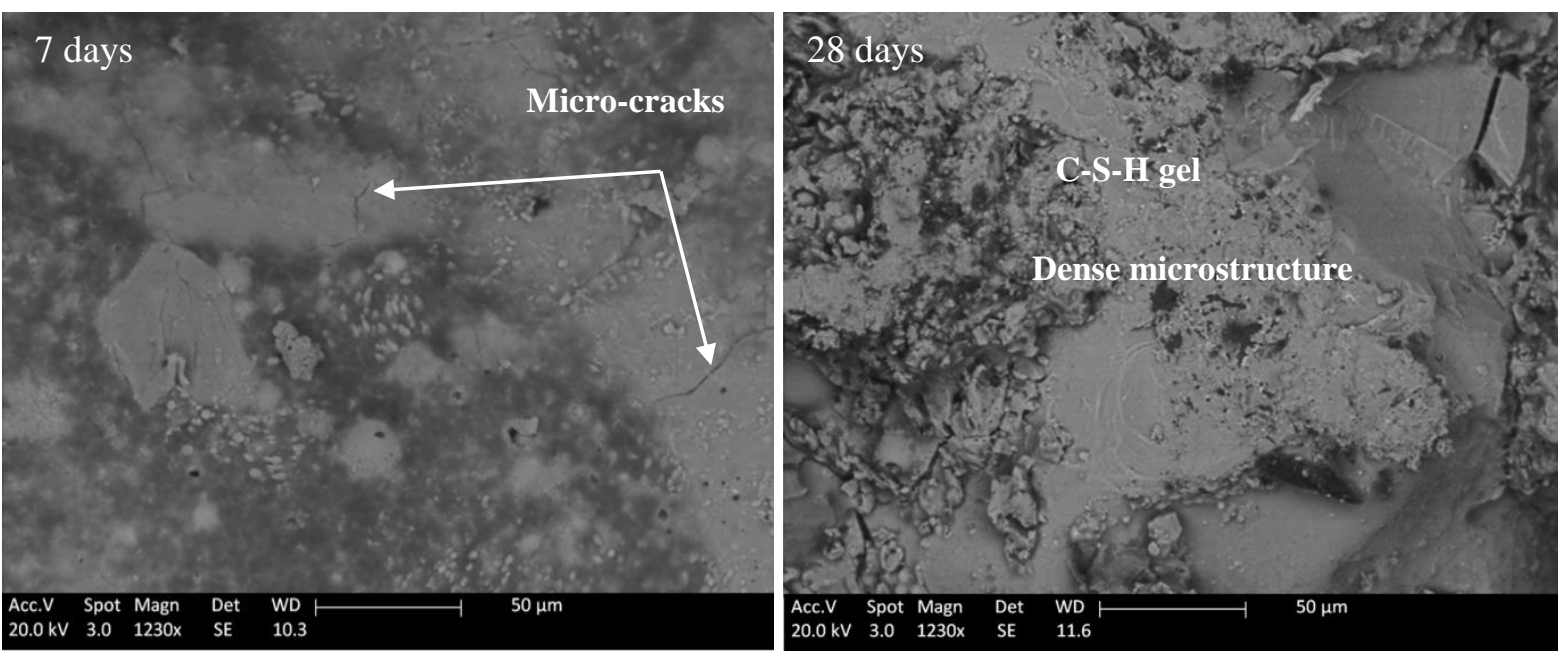

(b)

Fig. 4. SEM images of AAS concrete: (a) Normal strength concrete and (b) High strength concrete. 

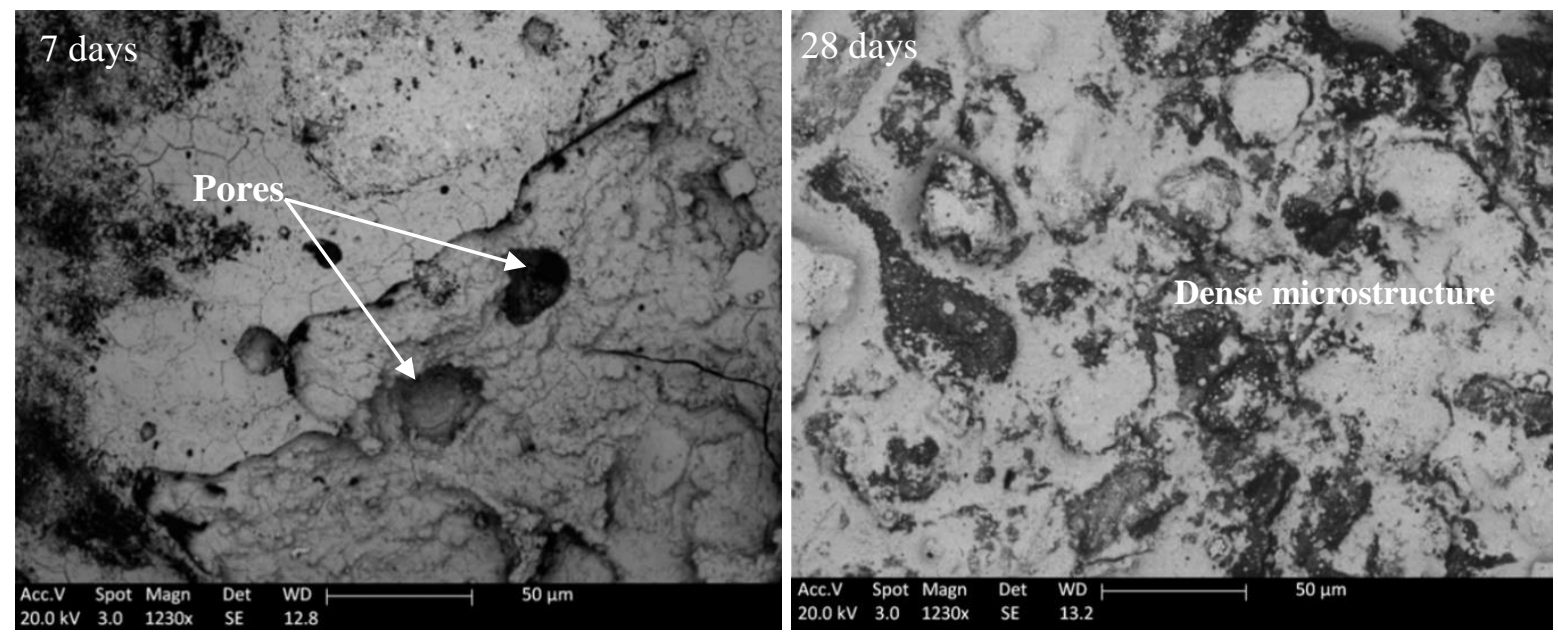

1065

(a)

1066
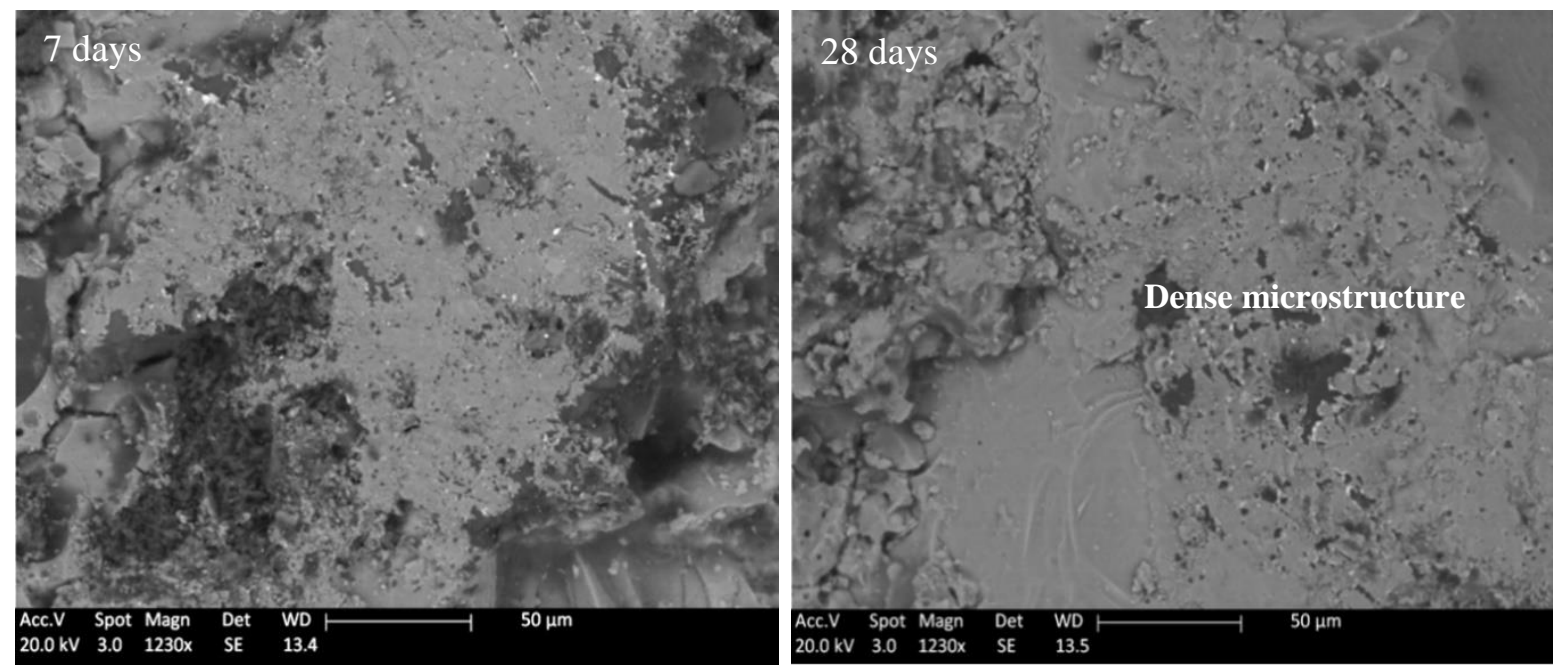

1068

(b)

Fig. 5. SEM images of OPC concrete: (a) Normal strength concrete and (b) High strength concrete. 


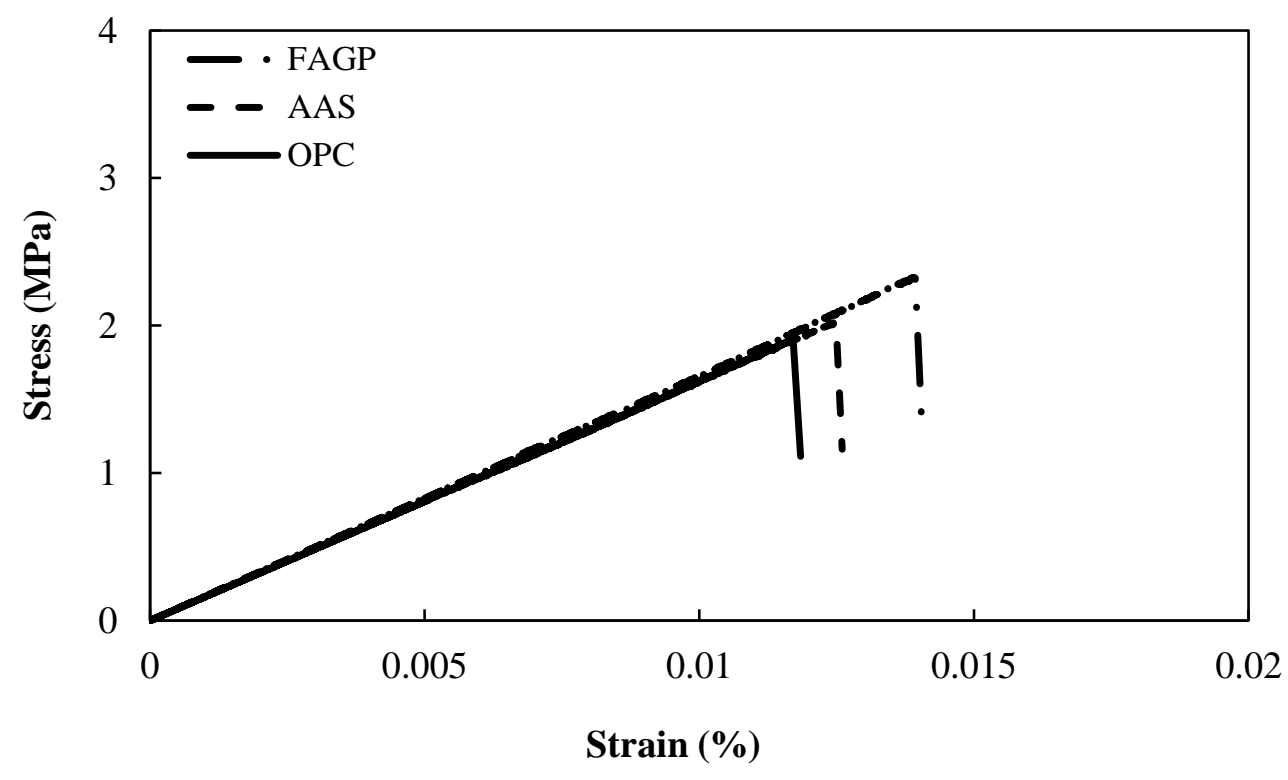

1074

(a)

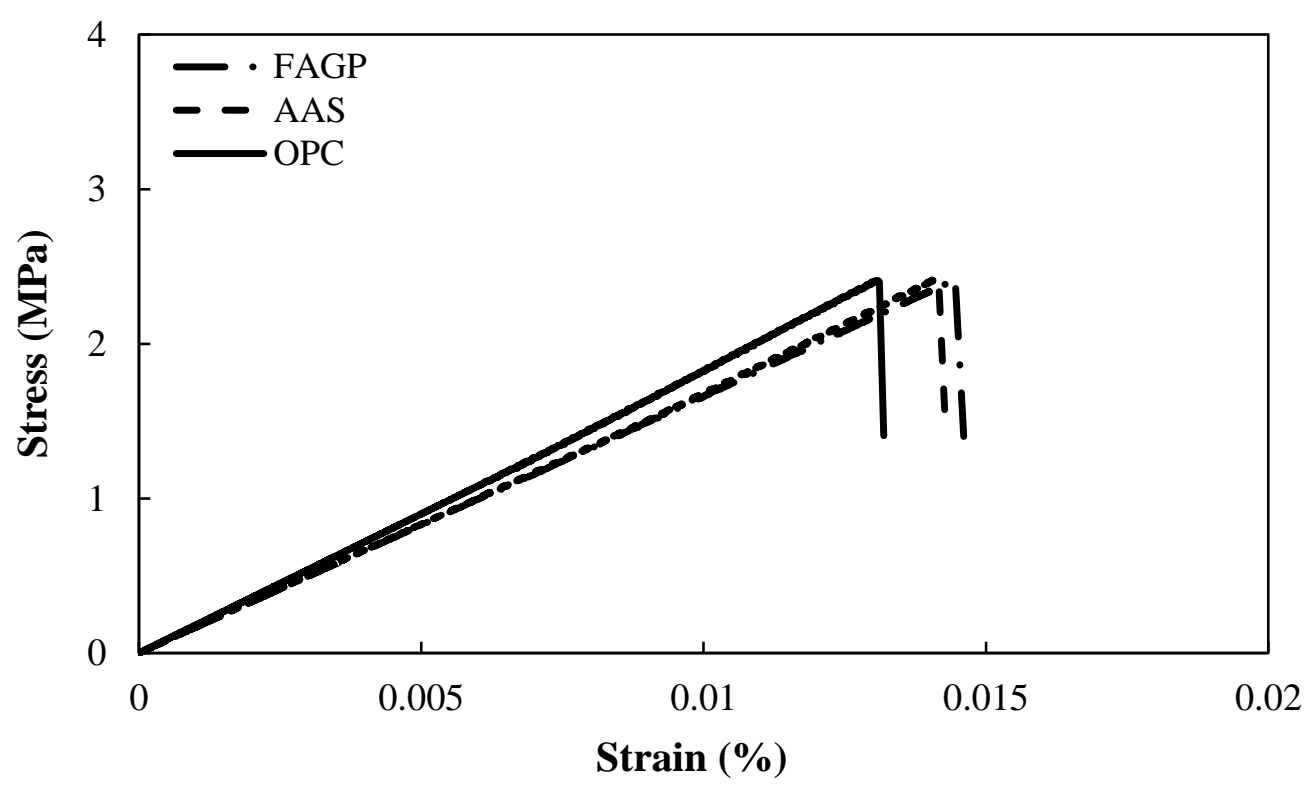

(b)

Fig. 6. Typical stress-strain behaviour under uniaxial tension for specimens of design compressive strength of $35 \mathrm{MPa}$ : (a) at 7 days and (b) at 28 days. 


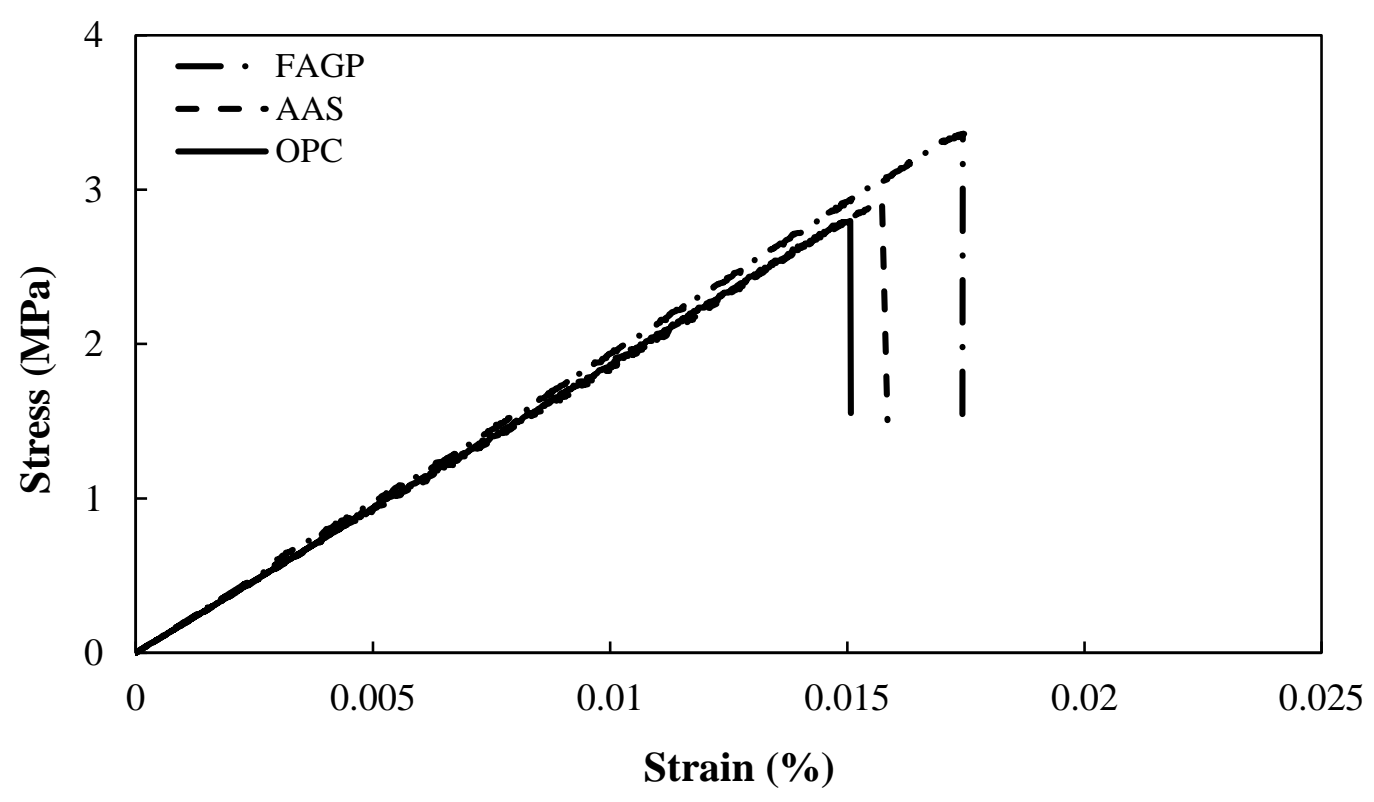

1080

(a)

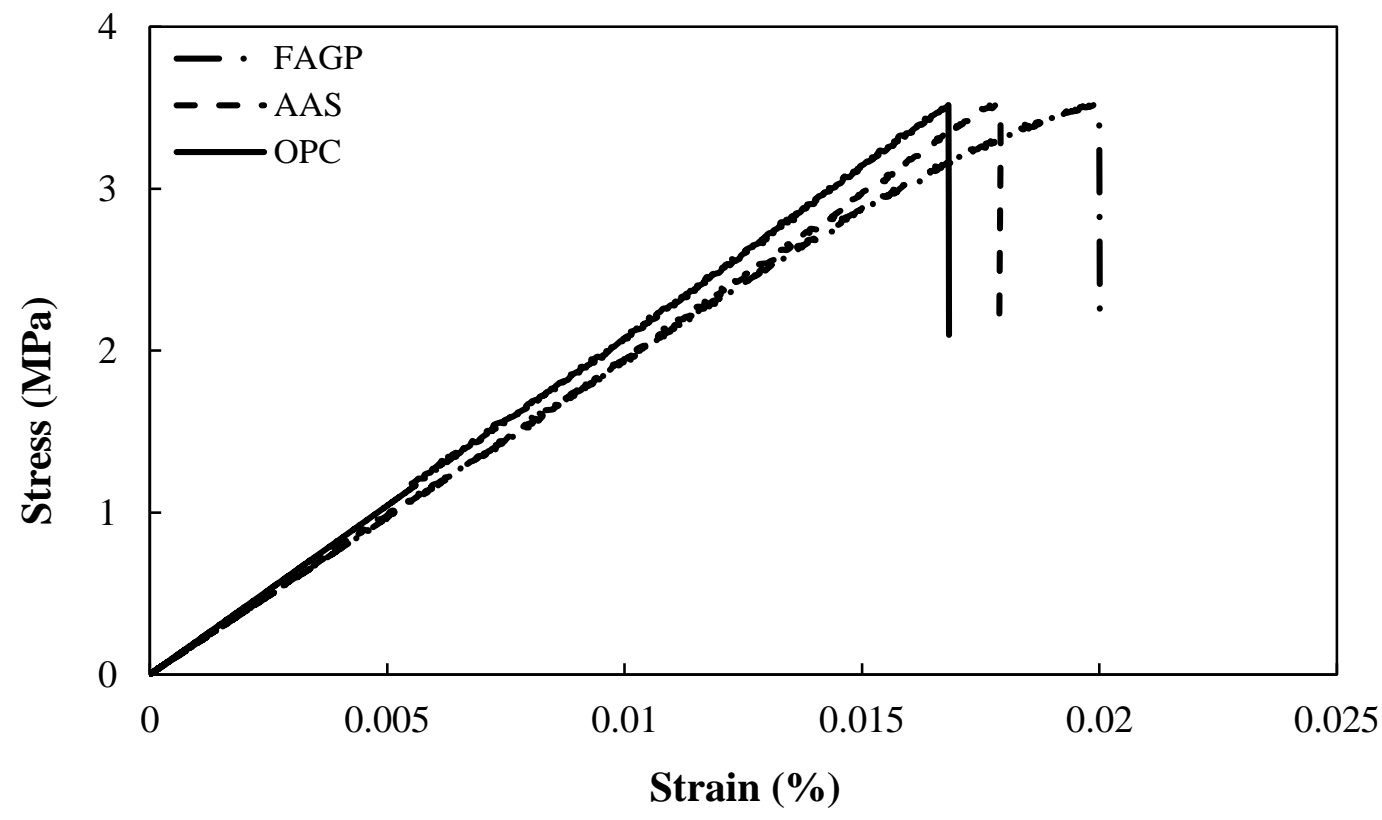

1081

(b)

1083

Fig. 7. Typical stress-strain behaviour under uniaxial tension for specimens of design compressive strength of $65 \mathrm{MPa}$ : (a) at 7 days and (b) at 28 days. 


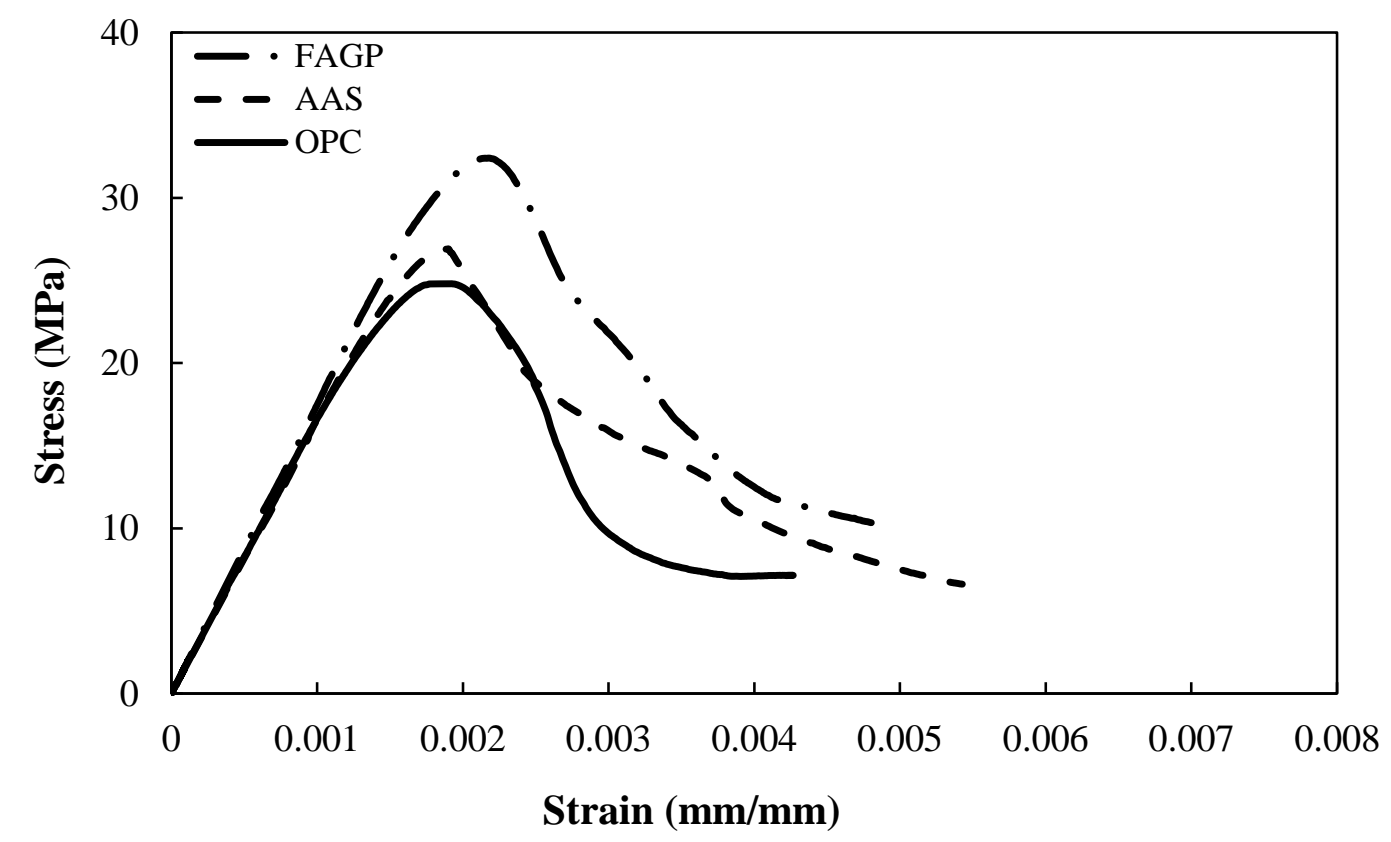

1086

(a)

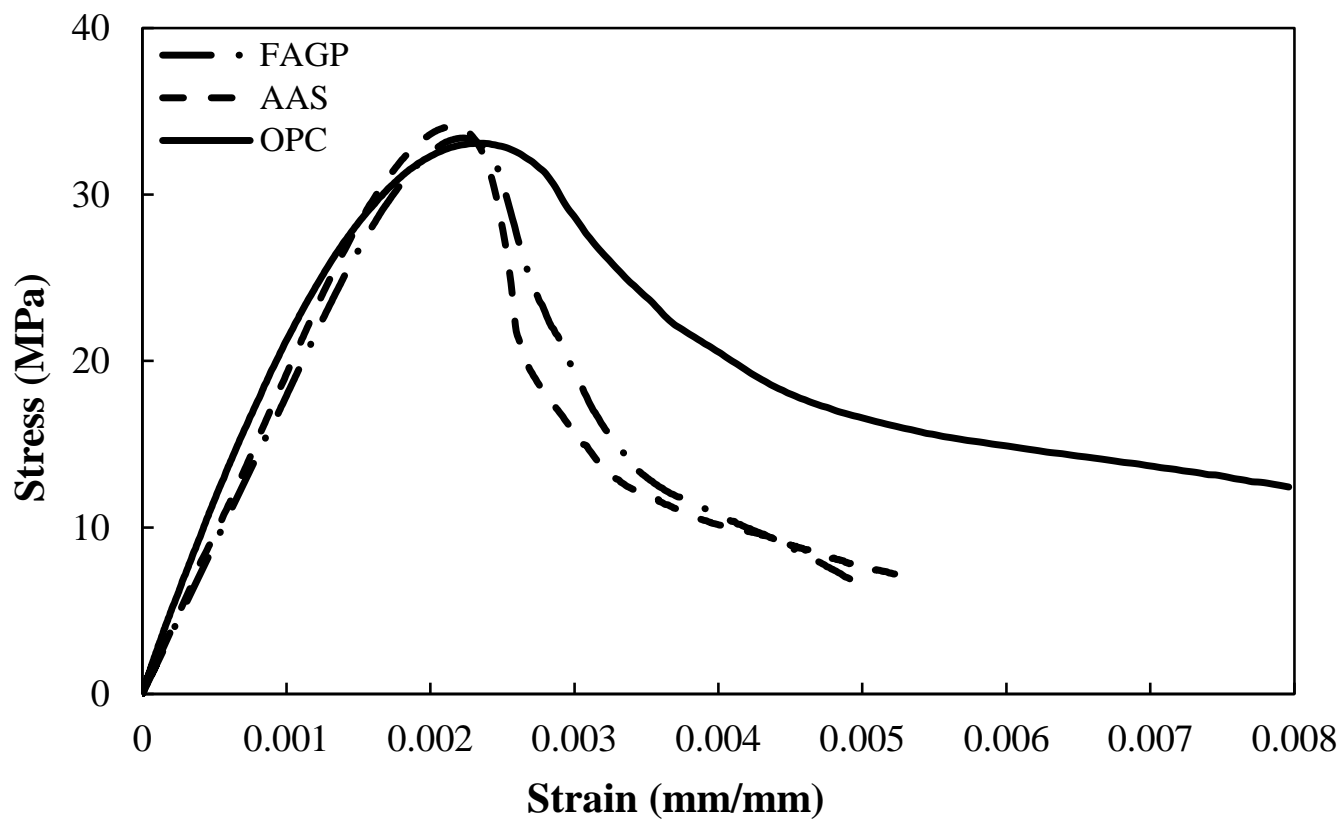

1088

(b)

1089

Fig. 8. Typical stress-strain behaviour under compression for specimens of design compressive strength of $35 \mathrm{MPa}$ : (a) at 7 days and (b) at 28 days. 


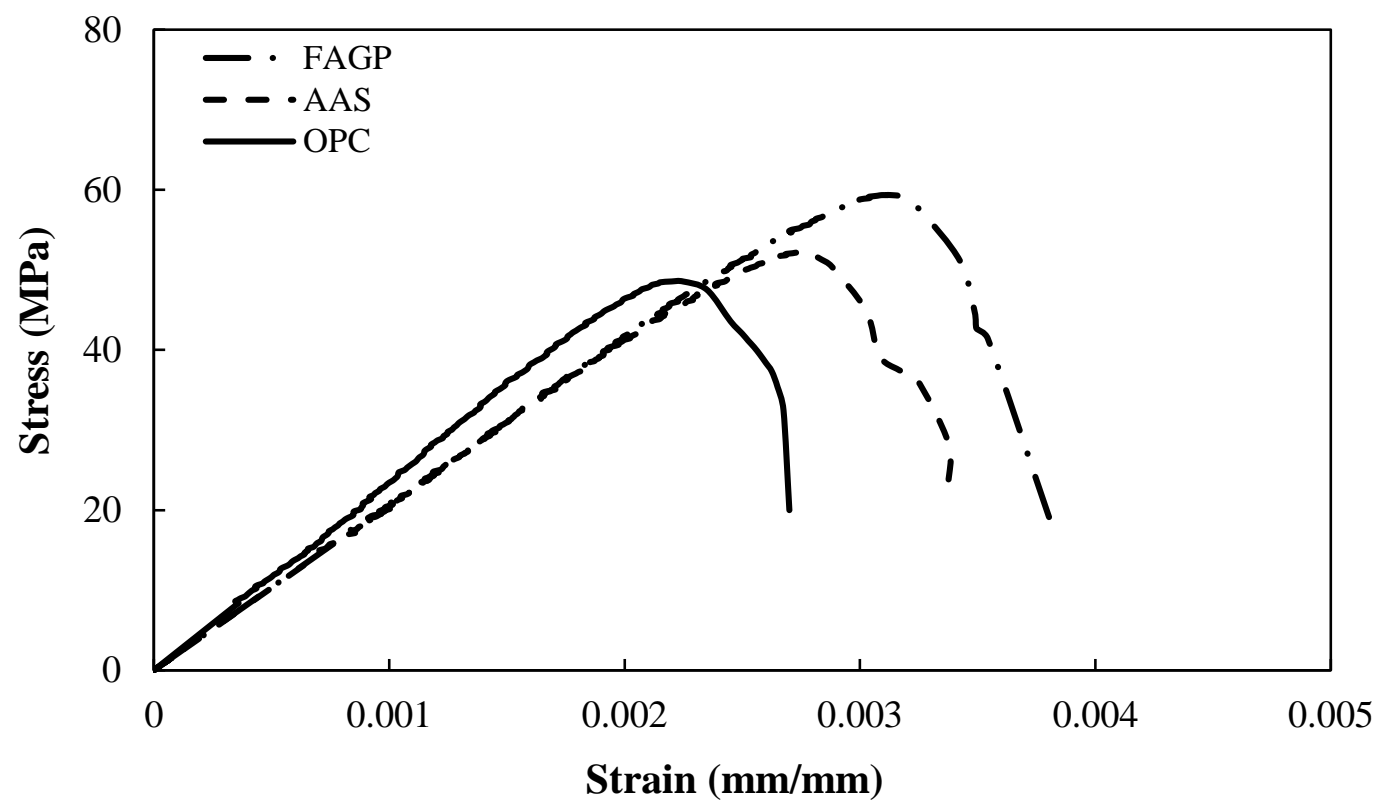

1091

(a)

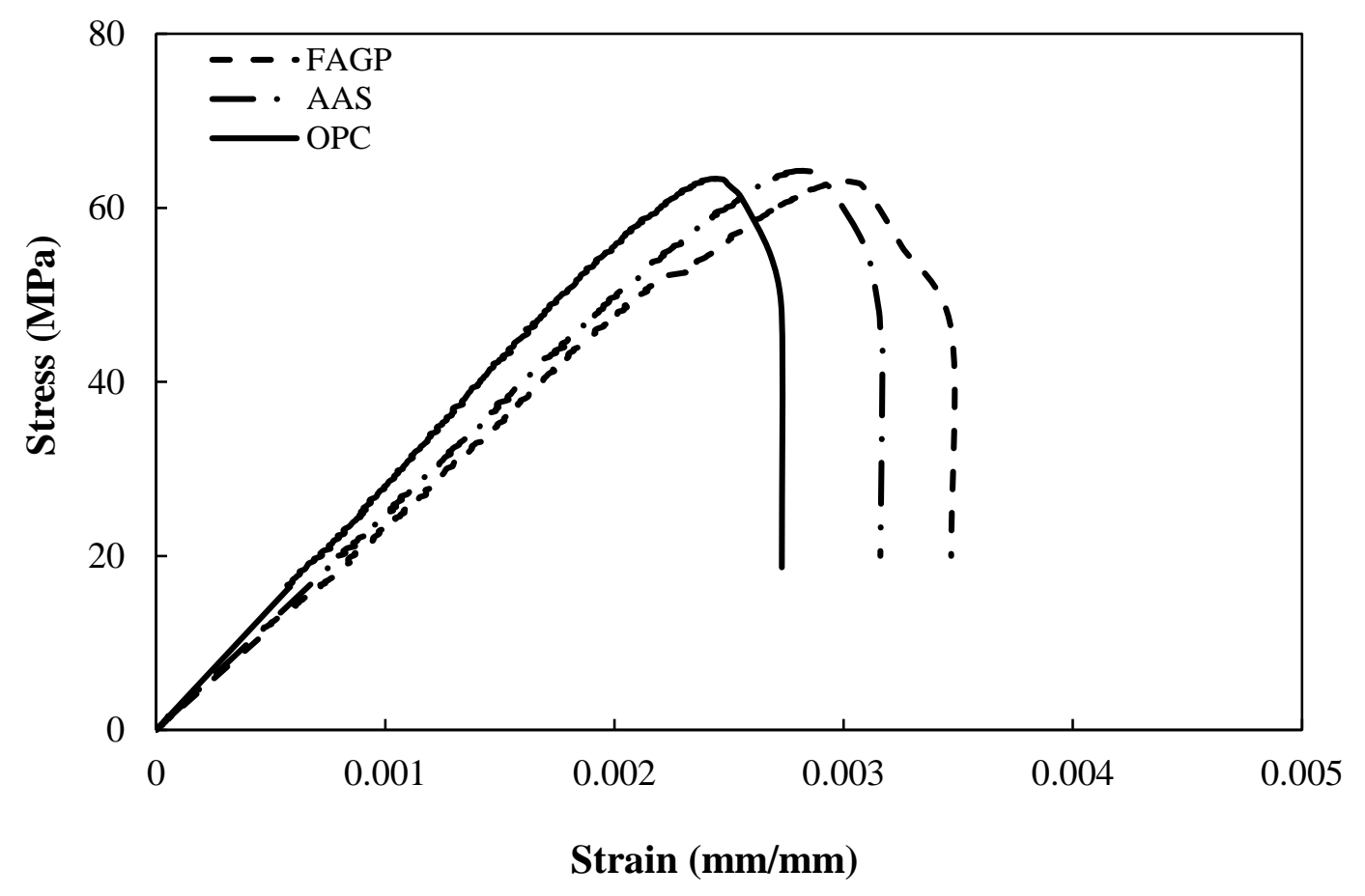

(b)

Fig. 9. Typical stress-strain behaviour under compression for specimens of design compressive strength of $65 \mathrm{MPa}$ (a) at 7 days and (b) at 28 days. 
1098

1099

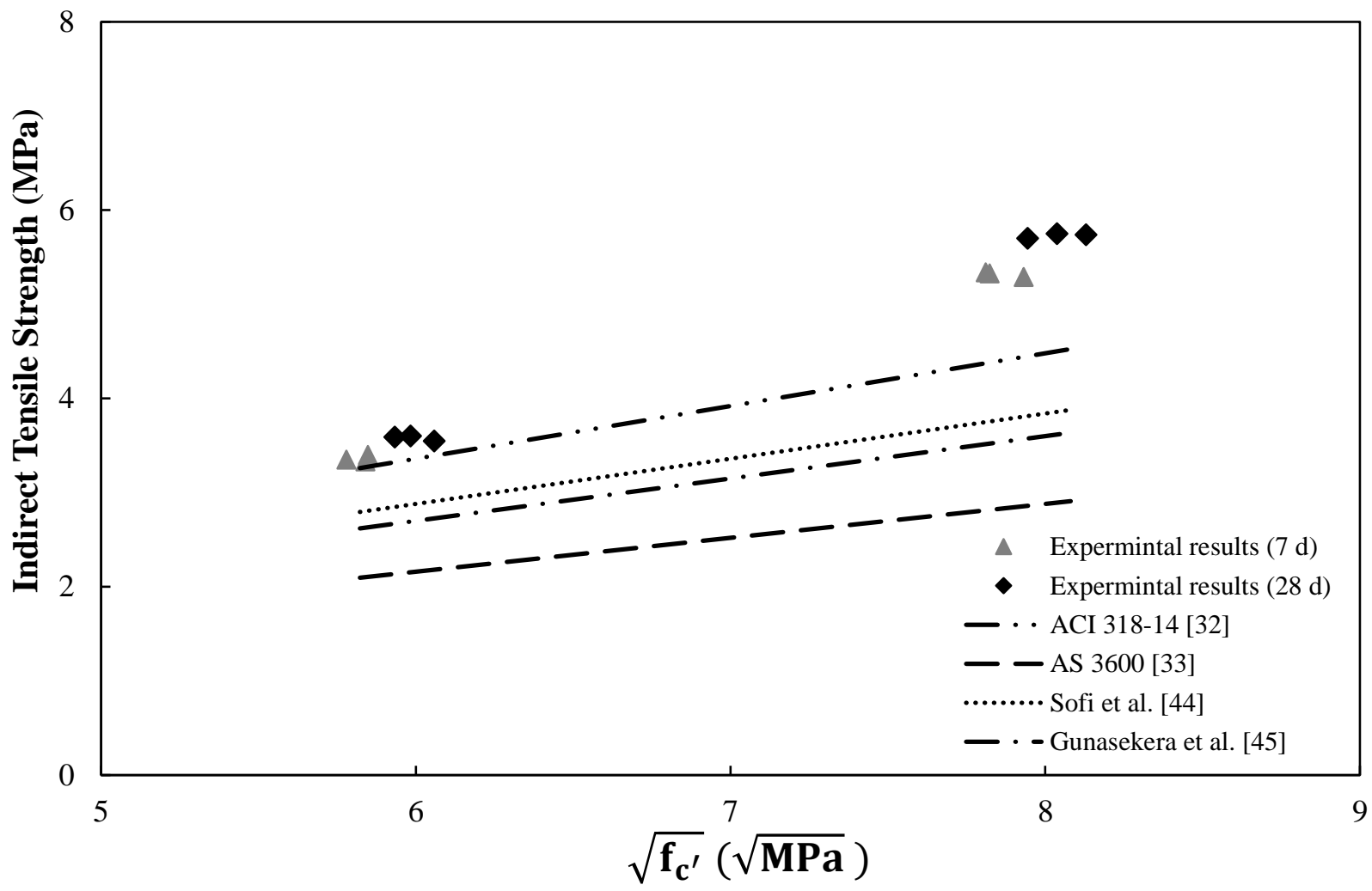

(a)

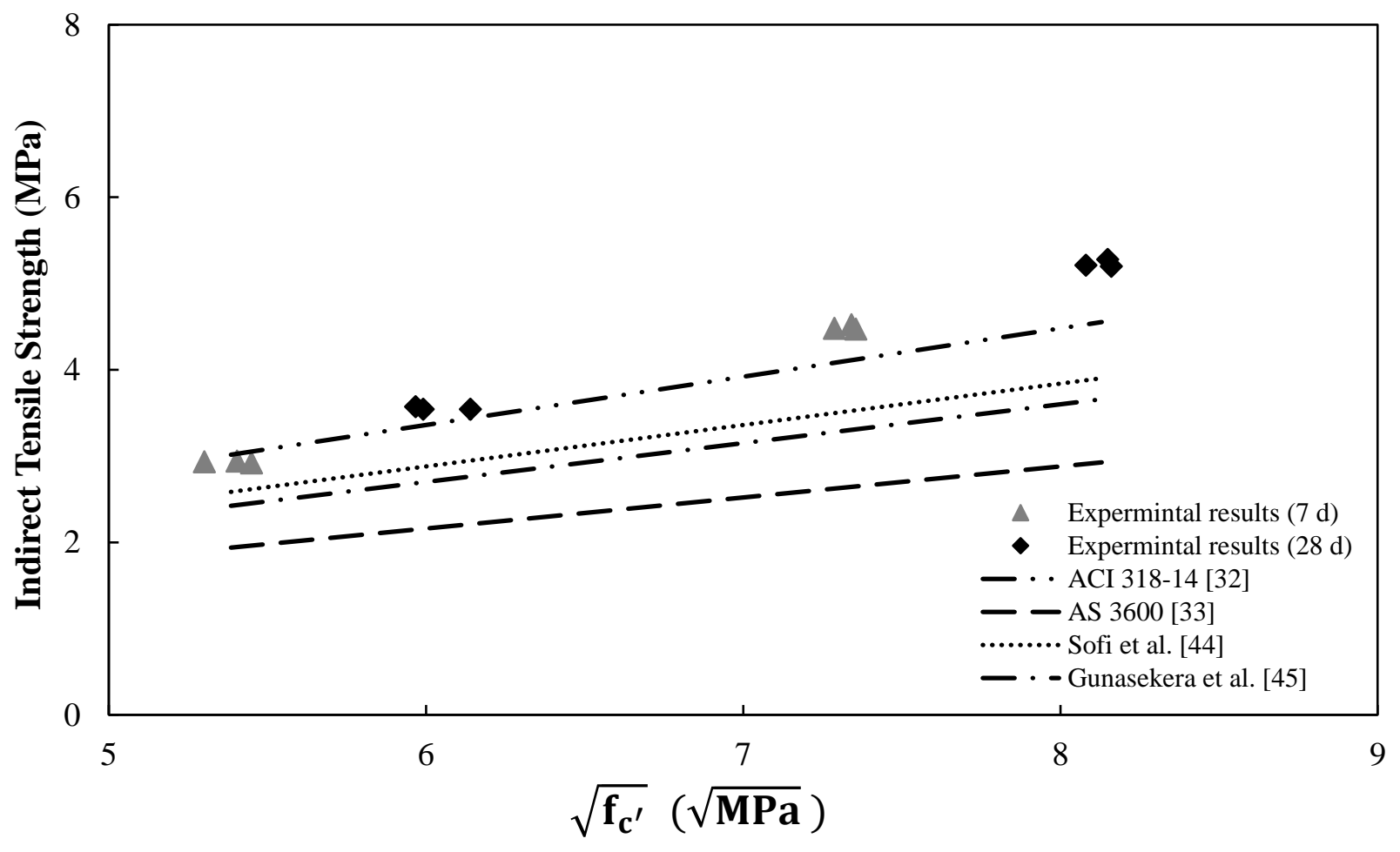

(b)

Fig. 10. Indirect tensile strength versus compressive strength: (a) FAGP concrete and (b)

AAS concrete. 


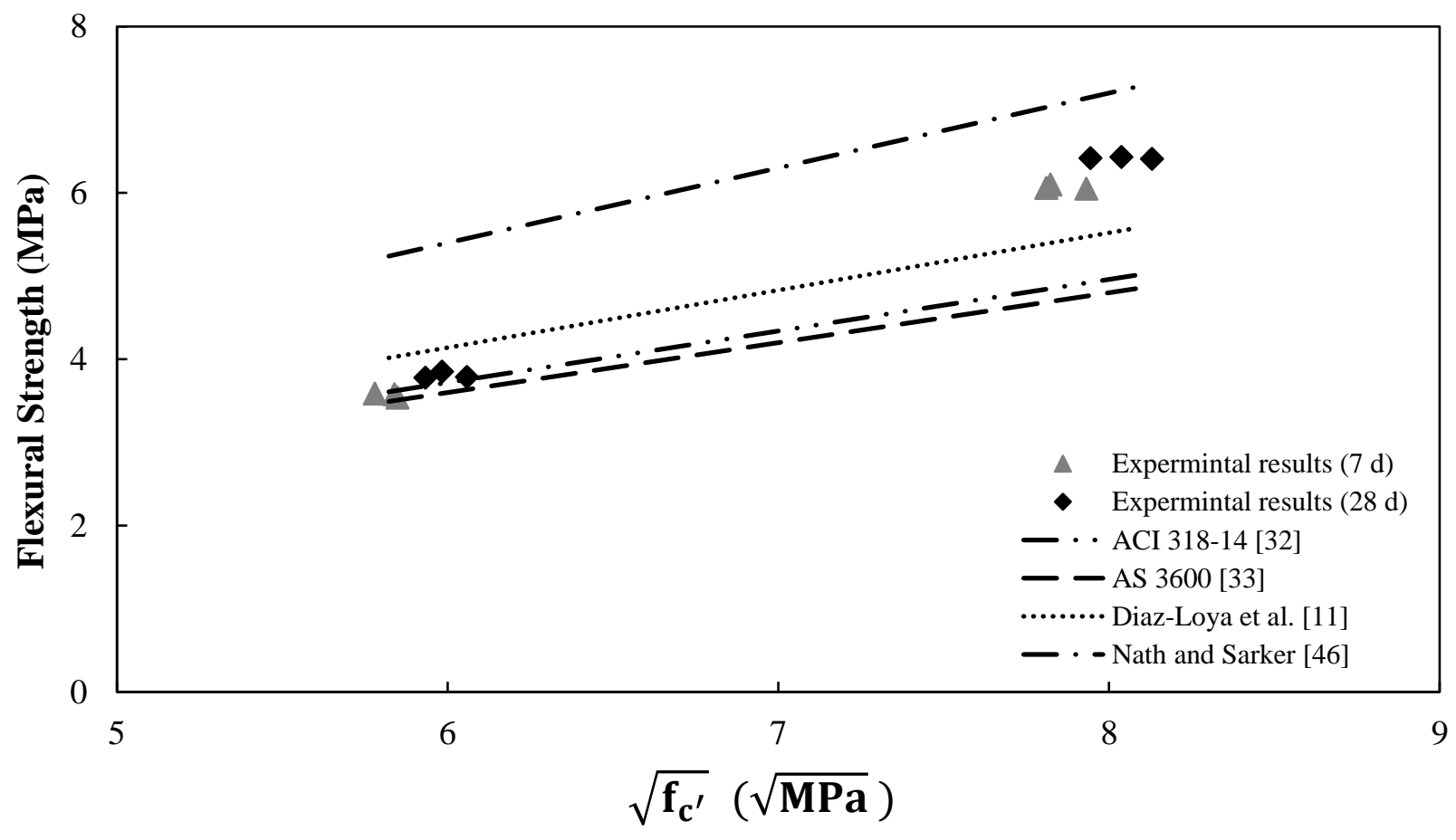

1105

(a)

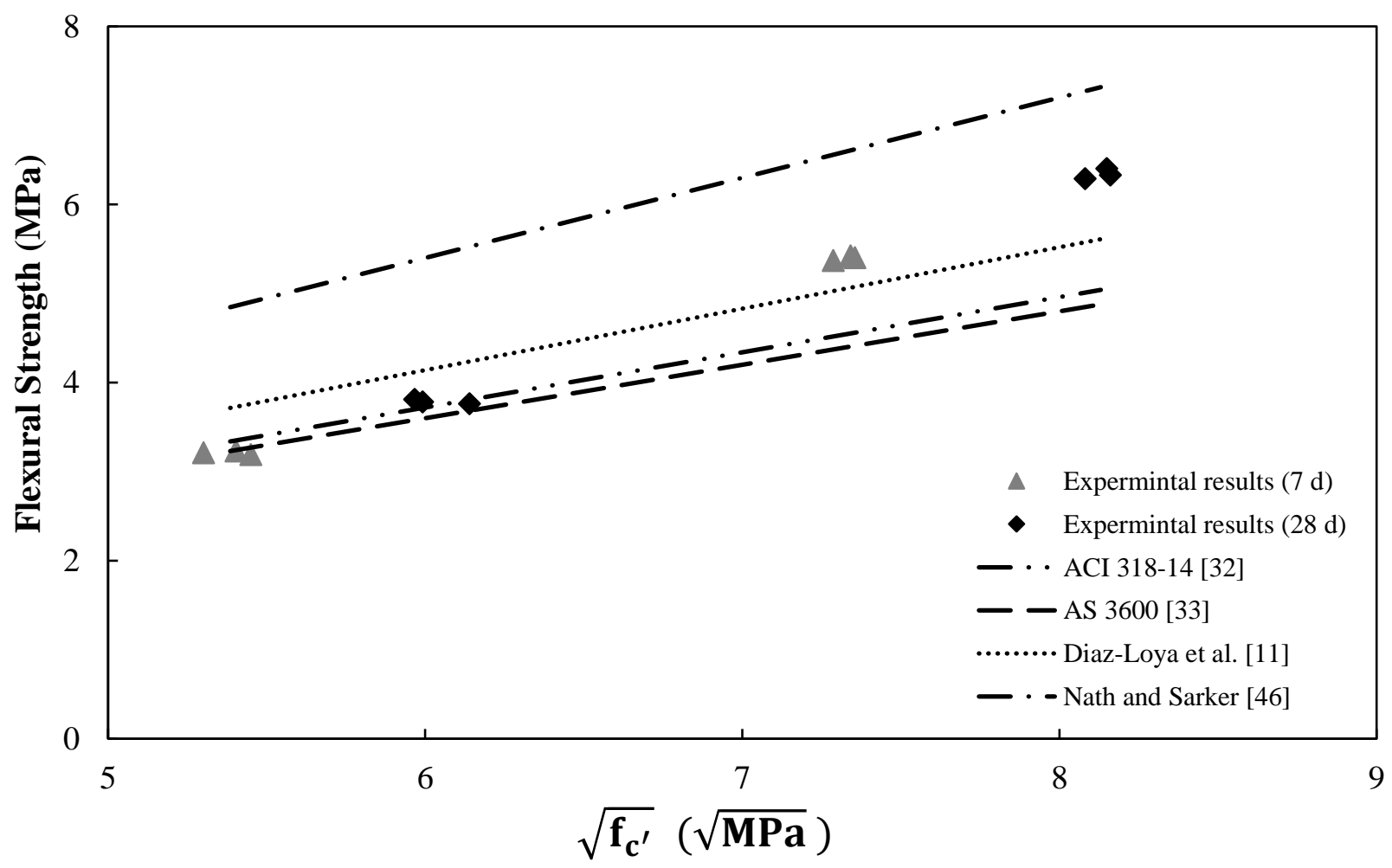

(b)

1108

Fig. 11. Flexural strength versus compressive strength: (a) FAGP concrete and (b) AAS concrete. 

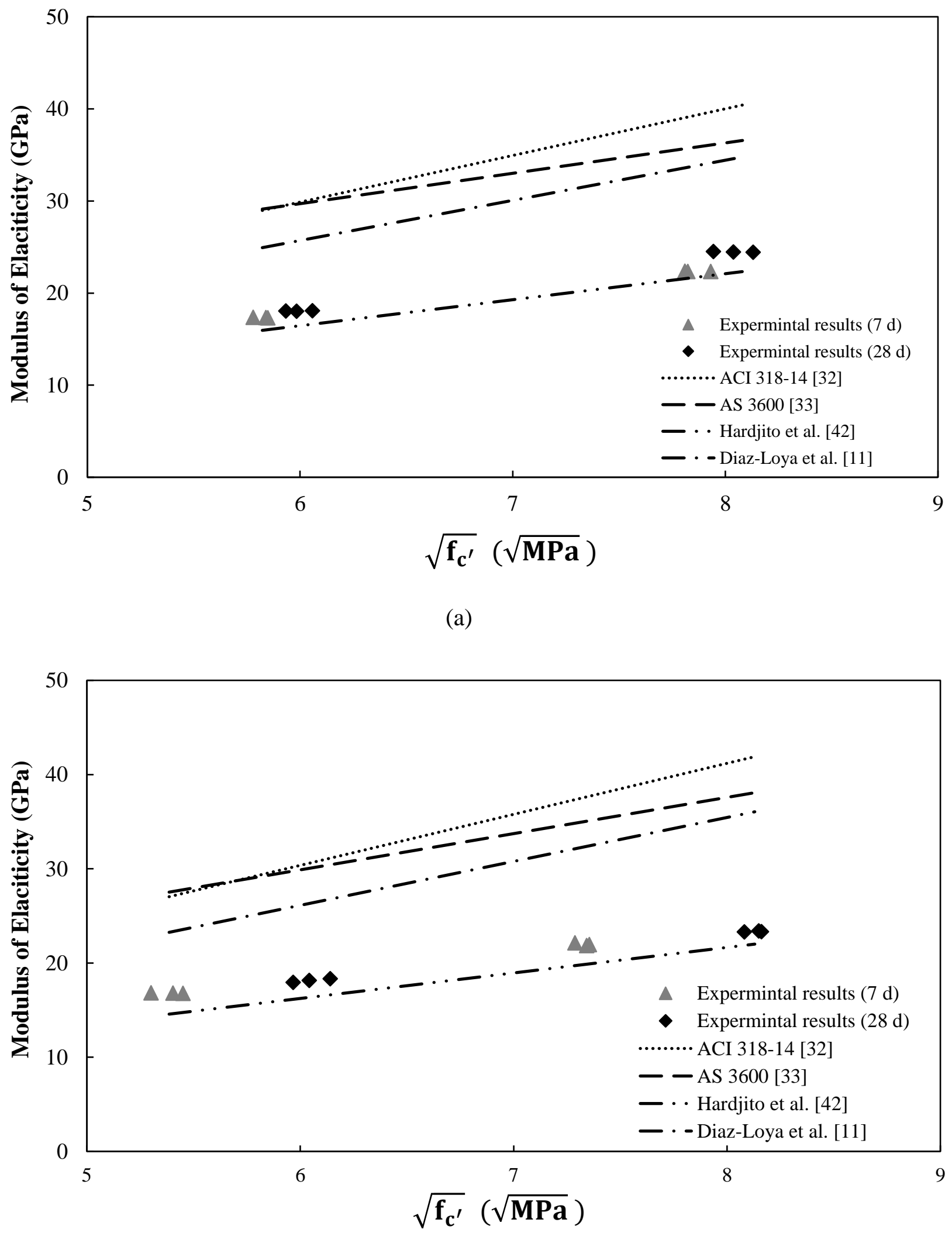

Fig. 12. Modulus of elasticity versus compressive strength: (a) FAGP concrete and (b) AAS concrete. 